Check for updates

Cite this: RSC Adv., 2017, 7, 40486

\title{
New phases of $3 d$-transition metal-cerium binary compounds: an extensive structural search $\dagger$
}

\author{
Xiaorui Sun, ${ }^{a}$ Yawei Lei, ${ }^{a}$ Rulong Zhou, (D) *a Bingyan Qu, ${ }^{a}$ Dongdong Li, ${ }^{a}$ Bo Zhang ${ }^{a}$ \\ and Xiao Cheng Zeng ${ }^{\star b c}$
}

We perform a comprehensive study to explore the low-energy crystalline phases of $3 \mathrm{~d}$ transitional metalcerium (TM-Ce) binary compounds using an unbiased structural search method coupled with firstprinciples optimization. For $\mathrm{Ce}-\mathrm{Sc}, \mathrm{Ce}-\mathrm{Ti}, \mathrm{Ce}-\mathrm{V}, \mathrm{Ce}-\mathrm{Cr}$ and $\mathrm{Ce}-\mathrm{Mn}$ binary systems, no stable crystalline phases are found from the structural search, offering an explanation for why none of these binary compounds have been observed in experiments. For $\mathrm{Ce}-\mathrm{Fe}, \mathrm{Ce}-\mathrm{Co}, \mathrm{Ce}-\mathrm{Ni}, \mathrm{Ce}-\mathrm{Cu}$ and $\mathrm{Ce}-\mathrm{Zn}$ binary systems, in addition to the previously known experimental structures, we also find several new low-energy crystalline phases. The computed electronic structures show that $\mathrm{Ce}$ atoms are in different states in the predicted binary compounds. In the $\mathrm{Ce}-\mathrm{Fe}, \mathrm{Ce}-\mathrm{Co}$ and $\mathrm{Ce}-\mathrm{Ni}$ compounds, the $\mathrm{Ce} 4 \mathrm{f}$ electrons are partially itinerant so that $\mathrm{Ce}$ atoms tend to adopt intermediate valence states between $\mathrm{Ce}^{+4}$ and $\mathrm{Ce}^{+3}$ due to the hybridization among Ce-4f, Ce-5d states and $3 d$ states of TM. In the $\mathrm{Ce}-\mathrm{Cu}$ and $\mathrm{Ce}-\mathrm{Zn}$ binary compounds, the $\mathrm{Ce}-4 \mathrm{f}$ states are more localized with the charge state of Ce being close to $3+$. In particular, the ferromagnetic metal (FM)-rich phases of the $\mathrm{Ce}-\mathrm{Fe}, \mathrm{Ce}-\mathrm{Co}$ and $\mathrm{Ce}-\mathrm{Ni}$ compounds tend to exhibit FM ordering in their ground states, owing to the strong exchange interaction among metal elements, whereas the non-magnetic states are usually preferred for FM-deficient phases. Magnetic orderings are also found in some other TM-rich phases of $\mathrm{Ce}-\mathrm{Cu}$ and $\mathrm{Ce}-\mathrm{Zn}$ compounds, where the magnetic moments are located on the $\mathrm{Ce}$ atoms due to the Kondo effect. Mechanic properties of these compounds are also computed based on density functional theory methods. This systematic study offers significantly new data for Ce-based alloys and will be useful to understand the intriguing behavior of the Ce-4f electron, thereby calling for future experimental confirmation of the newly predicted phases of $\mathrm{Ce}-\mathrm{TM}$ compounds.

Received 27th June 2017

Accepted 8th August 2017

DOI: $10.1039 / c 7 r a 07103 e$

rsc.li/rsc-advances can exhibit different electronic states, i.e. diamagnetic $\mathrm{Ce}^{4+}([\mathrm{Xe}]$ $\left.4 \mathrm{f}^{0}\right)$, paramagnetic $\mathrm{Ce}^{3+}\left([\mathrm{Xe}] 4 \mathrm{f}^{1}\right)$, mixed valence or intermediate valence, thereby resulting in diverse properties such as superconductivity, ${ }^{9,10}$ heavy-fermion property, ${ }^{11,12}$ complex magnetic properties ${ }^{13-15}$ excellent catalytic properties ${ }^{16-18}$ and high glassforming ability, ${ }^{19,20}$ etc. The ability to adopt a different state for the Ce 4 f electron in Ce-based intermetallic compounds leads to an interplay between the Ruderman-Kittel-Kasuya-Yosida (RKKY) interaction and the Kondo effect, as described by the coupling constant $J_{\mathrm{cf}}$ that reflects the correlation between the electrons of the open $f$ subshell of $\mathrm{Ce}$ and the conduction electrons in the intermetallic compounds. ${ }^{21} J_{\mathrm{cf}}$ is dependent on temperature, and can be modified by pressure and chemical bonding as well. So different Ce-based intermetallic compounds may exhibit very different properties at different compositions, with different crystal structures and different distances between Ce atoms etc.

It is also known that the multi-valence-states of Ce can lead to richer phases of Ce-based intermetallic compounds. For example, for the $\mathrm{Ce}-\mathrm{Al}$ binary compounds, crystalline phases of $\mathrm{Ce}_{1} \mathrm{Al}_{1},{ }^{22} \mathrm{Ce}_{1} \mathrm{Al}_{2},{ }^{23} \mathrm{Ce}_{1} \mathrm{Al}_{3},{ }^{24} \mathrm{Ce}_{1} \mathrm{Al}_{4}$ (ref. 25) and $\mathrm{Ce}_{3} \mathrm{Al}_{1}$ (ref. 26)
${ }^{a}$ Laboratory of Amorphous Matter and Science, School of Materials Science and Engineering, Hefei University of Technology, Hefei, Anhui 230009, China. E-mail: rlzhou@hfut.edu.cn

${ }^{b}$ Department of Chemistry, University of Nebraska-Lincoln, Lincoln, Nebraska 68588, USA. E-mail: xzeng1@unl.edu

${ }^{c}$ Collaborative Innovation Center of Chemistry for Energy Materials, University of Science and Technology of China, Hefei, Anhui 230026, China

$\dagger$ Electronic supplementary information (ESI) available. See DOI: 10.1039/c7ra07103e 
were synthesized experimentally, and they exhibit very different physical properties. ${ }^{27-31}$ Among all the Ce-based binary compounds, the $\mathrm{Ce}$ and transition metal (Ce-TM) are of particular significance due to the interplay between the $4 \mathrm{f}$ electrons of Ce and $3 \mathrm{~d}$ electrons of transition metals, which can lead to rich physical properties. For examples, $\mathrm{Ce}_{1} \mathrm{Cu}_{6}$ is known to be a heavy-fermion system, ${ }^{11}$ while $\mathrm{Ce}_{1} \mathrm{Cu}_{2}$ exhibits magnetic ordering and Kondo effects. ${ }^{32}$ And with the same crystalline structure, $\mathrm{Ce}_{1} \mathrm{Co}_{2}$ and $\mathrm{Ce}_{1} \mathrm{Ni}_{2}$ exhibit paramagnetic or nonmagnetic property. ${ }^{33,34}$ Although considerable efforts have been made for the synthesis of Ce-TM binary compounds in the past decades, only several crystalline phases were successfully synthesized. To date, stable crystal structures of Ce-Sc, Ce-Ti, $\mathrm{Ce}-\mathrm{V}, \mathrm{Ce}-\mathrm{Cr}$ and $\mathrm{Ce}-\mathrm{Mn}$ binary compounds have not been reported in the literature, although some special crystalline structures have been found for the Ce-TM binary compounds, such as $\mathrm{Ce}_{1} \mathrm{X}_{2}$ and $\mathrm{Ce}_{1} \mathrm{X}_{5}(\mathrm{X}=\mathrm{Fe}, \mathrm{Co}, \mathrm{Ni}, \mathrm{Cu}, \mathrm{Zn}), \mathrm{CeX}(\mathrm{X}=\mathrm{Ni}$, $\mathrm{Cu}, \mathrm{Zn}$ ), $\mathrm{Ce}_{1} \mathrm{Cu}_{6}$ and $\mathrm{Ce}_{1} \mathrm{Ni}_{3}$ (obtained from Inorganic Crystal Structure Database), etc. Much more stable crystalline phases of Ce-TM binary compounds are expected to exist even though they have not been synthesized from experiments. Theoretical predictions of new structures of Ce-TM binary compounds would be helpful to guide future experimental synthesis.

With the state-of-the art global structure search methods, such as genetic algorithm, simulated annealing, topological modeling, and molecular packing, it is possible to identify new crystalline phases of Ce-TM binary compounds. In this study, we perform a systematic search for the stable and low-energy metastable crystalline structures of Ce-TM binary compounds $\mathrm{Ce}_{m} \mathrm{TM}_{n}$ (where $\mathrm{TM}=\mathrm{Sc}$, Ti, $\mathrm{V}, \mathrm{Cr}, \mathrm{Mn}, \mathrm{Fe}, \mathrm{Co}, \mathrm{Ni}, \mathrm{Cu}, \mathrm{Zn}$ ) using an evolutionary algorithm combined with first-principles optimization. Besides experimentally observed phases, we found several new low-energy crystalline phases of Ce-TM (TM = Fe, $\mathrm{Co}, \mathrm{Ni}, \mathrm{Cu}, \mathrm{Zn}$ ). Detailed structures, electronic and mechanical properties of the new phases are described below.

\section{Computational method}

An unbiased search of stable structures of $\mathrm{Ce}_{m} \mathrm{X}_{n}$ is performed using the USPEX package. ${ }^{35,36}$ The selected method is based on an evolutionary algorithm which has been proven to be reliable in identifying new phases of a number of systems. ${ }^{37-40}$ The varying composition search method is applied to seek the most optimal composition of each system. Various compositions with the $m: n$ ratios ranging from $1: 7$ to $7: 1$ with the constraint of $m+n \leq 8$ are explored. Medium-sized unit cells containing 8-16 atoms are considered. Three hundreds of structures are generated in the first generation which ensures diversity of the structures at each composition. Sixty structures with different compositions are generated in the ensuing generations by using different evolutionary operations to the low-energy structures, including heredity (60\% structures), soft mutation $(20 \%)$, transmutation $(10 \%)$ and random production $(10 \%)$. All the structures are optimized using VASP package ${ }^{41}$ to achieve medium accuracy. Based on the computed energy of each structure, a rough convex-hull curve of formation energy is plotted, from which possible energetically stable structures and phases are selected out for further structural optimization at higher accuracy.

The structures which are located on or slightly above the convex-hull are picked out for re-optimization using VASP package. The Perdew-Burke-Enzerhof $\quad(\mathrm{PBE})^{42}$ exchangecorrelation functional within the generalized gradient approximation (GGA) is used. We will point that although usually a Hubbard U correction should be considered for d- and f-elements, our calculations show that standard GGA calculations can give consistent results with experiments for the Ce-TM binary compounds concerned. Furthermore, GGA without $\mathrm{U}$ calculations were also performed in many previous theoretical works about Ce-based intermetallic compounds and also showed great success. ${ }^{34,43,44}$ During the structural optimization, an all-electron plane-wave basis set with the energy cutoff of $300 \mathrm{eV}$ and the $k$-point spacing smaller than $2 \pi \times$ $0.03 \AA^{-1}$ in the Brillouin zone is used. It is done until the residual force acting on each atom is less than $0.01 \mathrm{eV}^{-1}$. Then more accurate calculations with larger energy cutoff of $600 \mathrm{eV}$ and denser $k$-point (less than $2 \pi \times 0.02 \AA^{-1}$ ) are performed to get more accurate formation energies. Thus, relative stabilities of different structures with the same composition and those with different compositions are found based on the computed convex-hull of formation energy. Furthermore, to assure that no stable phases are missed in the structural search, we also examined structures and phases not seen from the structural search but are stable for other systems. By comparing their formation energies against those structures obtained from the structural search, we can determine the phase stability of each system with more confidence.

To check dynamic stability of all the predicted structures, phonon spectrum, using the finite-displacement approach, is calculated as implemented in the Phonopy code ${ }^{45}$ (combined with VASP). Moreover, the elastic constants of all the structures are calculated using the stress-strain relations. Mechanical stabilities of these structures can be examined according to the Born stability criteria. ${ }^{46-48}$ From the calculated stiffness constants $C_{i j}$ and the compliance $S_{i j}$, the Voigt and Reuss bulk and shear moduli are calculated according to the following formula: ${ }^{49}$

$$
\begin{aligned}
& B_{\mathrm{V}}= \frac{1}{9}\left[\left(C_{11}+C_{22}+C_{33}\right)+2\left(C_{12}+C_{23}+C_{31}\right)\right] \\
& G_{\mathrm{V}}= \frac{1}{15}\left[\left(C_{11}+C_{22}+C_{33}\right)-\left(C_{12}+C_{13}+C_{23}\right)\right. \\
&\left.+3\left(C_{44}+C_{55}+C_{66}\right)\right] \\
& B_{\mathrm{R}}= \frac{1}{\left(S_{11}+S_{22}+S_{33}\right)+2\left(S_{12}+S_{23}+S_{13}\right)} \\
& G_{\mathrm{R}}=\frac{15}{4\left(S_{11}+S_{22}+S_{33}\right)-\left(S_{12}+S_{23}+S_{13}\right)+3\left(S_{44}+S_{55}+S_{66}\right)}
\end{aligned}
$$

where $B_{\mathrm{V}}, G_{\mathrm{V}}$ and $B_{\mathrm{R}}, G_{\mathrm{R}}$ are the Voigt bulk and shear moduli, and Reuss bulk and shear moduli respectively. The Voigt and Reuss elastic moduli can be viewed as the upper and lower 
bound respectively. In this study, the averaged bulk and shear moduli, $B=\left(B_{\mathrm{V}}+B_{\mathrm{R}}\right) / 2$ and $G=\left(G_{\mathrm{V}}+G_{\mathrm{R}}\right) / 2$, are adopted according to Voigt-Reuss-Hill approximations. ${ }^{49}$

\section{Results and discussion}

\subsection{Phase stabilities}

We have performed an extensive search for structures of the Ce-TM binary compounds of all $3 \mathrm{~d}$ transition metals. To determine whether the binary compound of $\mathrm{Ce}_{1-x} \mathrm{TM}_{x}$ can be formed and is stable against decomposition into its pure constituents, we calculated the formation enthalpies of all the structures obtained from the search according to the following formula:

$$
\Delta H\left(\mathrm{Ce}_{1-x} \mathrm{TM}_{x}\right)=H\left(\mathrm{Ce}_{1-x} \mathrm{TM}_{x}\right)-(1-x) H(\mathrm{Ce})-x H(\mathrm{TM})
$$

where $H\left(\mathrm{Ce}_{1-x} \mathrm{TM}_{x}\right), H(\mathrm{Ce})$ and $H(\mathrm{TM})$ are the enthalpy per atom of the compound $\mathrm{Ce}_{1-x} \mathrm{TM}_{x}$, pure Ce and pure TM, respectively. Based on the calculated formation enthalpies, the convex-hull curves of all the systems are plotted, as shown in Fig. 1. The phases which are located at the vertex of the convex-hull are stable to resist decomposition into their pure constituents or phases of other compositions. Before the analysis, dynamic stabilities of the predicted energetically stable phases are examined. As shown in Fig. S1 (see the ESI $\dagger$ ), all the predicted energetically stable structures are dynamically stable without any imaginary frequencies. According to the mechanical stability criteria, ${ }^{46-48}$ all these phases are also mechanically stable based on the calculated elastic constants listed in Table S1. $\dagger$

For Ce-Sc, Ce-Ti, Ce-V, Ce-Cr and Ce-Mn, no stable phases were found from the structural search since the formation enthalpies of all the searched structures are positive. So, for TM $=\mathrm{Sc}, \mathrm{Ti}, \mathrm{V}, \mathrm{Cr}$, and $\mathrm{Mn}, \mathrm{Ce}-\mathrm{TM}$ binary compounds are unlikely to form. For $\mathrm{Ce}-\mathrm{Fe}, \mathrm{Ce}-\mathrm{Co}, \mathrm{Ce}-\mathrm{Ni}, \mathrm{Ce}-\mathrm{Cu}$ and $\mathrm{Ce}-\mathrm{Zn}$, interestingly, besides experimentally synthesized phases, some new structures are also found (see Fig. 1), which are also possible to be synthesized because of their low formation enthalpies.

Firstly, for the Ce-Fe binary compounds, a new phase of $\mathrm{Ce}_{1} \mathrm{Fe}_{1}-\mathrm{p}$ is found, which is located at the vertex of the convexhull curve, suggesting its high stability. We also found a phase of $\mathrm{Ce}_{2} \mathrm{Fe}_{1}$-p whose formation energy lies slightly above the convex-hull curve, similar to $\mathrm{Ce}_{1} \mathrm{Fe}_{2}$-e and $\mathrm{Ce}_{1} \mathrm{Fe}_{5}$-e. Since both $\mathrm{Ce}_{1} \mathrm{Fe}_{2}$-e and $\mathrm{Ce}_{1} \mathrm{Fe}_{5}$-e are experimentally synthesized, the structure of $\mathrm{Ce}_{2} \mathrm{Fe}_{1}-\mathrm{p}$ may also have possibility of being synthesized under certain conditions.

Secondly, for the Ce-Co binary compounds, besides previously synthesized phases of $\mathrm{Ce}_{1} \mathrm{Co}_{2}$-e and $\mathrm{Ce}_{1} \mathrm{Co}_{5}$-e, two new phases, $\mathrm{Ce}_{2} \mathrm{Co}_{1}-\mathrm{p}$ and $\mathrm{Ce}_{1} \mathrm{Co}_{1}-\mathrm{p}$, are predicted. $\mathrm{Ce}_{2} \mathrm{Co}_{1}-\mathrm{p}$, $\mathrm{Ce}_{1} \mathrm{Co}_{1}-\mathrm{p}$ and $\mathrm{Ce}_{1} \mathrm{Co}_{2}$-e are located at the vertex of the convexhull of formation energy, while $\mathrm{Ce}_{1} \mathrm{Co}_{5}$-e lies slightly above. So, $\mathrm{Ce}_{2} \mathrm{Co}_{1}-\mathrm{p}$ and $\mathrm{Ce}_{1} \mathrm{Co}_{1}-\mathrm{p}$ are also likely to be synthesized.

Thirdly, for the Ce-Ni binary compounds, stable structures $\mathrm{Ce}_{1} \mathrm{Ni}_{1}-\mathrm{e}, \mathrm{Ce}_{1} \mathrm{Ni}_{2}-\mathrm{e}, \mathrm{Ce}_{1} \mathrm{Ni}_{3}-\mathrm{e}$ and $\mathrm{Ce}_{1} \mathrm{Ni}_{5}-\mathrm{e}$ have been synthesized experimentally. The experimental structure of $\mathrm{Ce}_{1} \mathrm{Ni}_{3}$-e cannot be found from our structural search as it contains 24 atoms in the primitive cell while we constrained the max number of atoms $\leq 16$ in the unit cell. The lowest-energy structure of the $\mathrm{Ce}_{1} \mathrm{Ni}_{3}-\mathrm{p}$ is $40 \mathrm{meV}$ higher in the formation energy than the experimental structure. Hence the experimental structure of $\mathrm{Ce}_{1} \mathrm{Ni}_{3}$-e is stable. A new phase of $\mathrm{Ce}_{1} \mathrm{Ni}_{1}-\mathrm{p}$ is obtained from the search, which is more than $100 \mathrm{meV}$ lower in the calculated formation energy than the experimental structure. So, $\mathrm{Ce}_{1} \mathrm{Ni}_{1}-\mathrm{p}$ is also likely to be synthesized. The experimental phases of $\mathrm{Ce}_{1} \mathrm{Ni}_{3}-\mathrm{e}$ and $\mathrm{Ce}_{1} \mathrm{Ni}_{5}$-e are all located at the vertex of the convexhull, indicating that these phases are stable. The experiment phase of $\mathrm{Ce}_{1} \mathrm{Ni}_{2}$-e lies just above the convex-hull curve.

Fourthly, for the $\mathrm{Ce}-\mathrm{Cu}$ system, three newly predicted structures $\left(\mathrm{Ce}_{1} \mathrm{Cu}_{1}-\mathrm{p}, \mathrm{Ce}_{1} \mathrm{Cu}_{3}-\mathrm{p}\right.$ and $\left.\mathrm{Ce}_{1} \mathrm{Cu}_{5}-\mathrm{p}\right)$ along with two synthesized structures $\left(\mathrm{Ce}_{1} \mathrm{Cu}_{2}\right.$-e and $\mathrm{Ce}_{1} \mathrm{Cu}_{6}$-e) give rise to the convex-hull suggesting these predicted structures are also likely to be synthesized.

Lastly, for the Ce-Zn system, stable crystalline compounds with at least five compositions may exist according to the computed convex-hull. The experimental structures of $\mathrm{Ce}_{1} \mathrm{Zn}_{2}-\mathrm{e}$, $\mathrm{Ce}_{1} \mathrm{Zn}_{3}$-e and $\mathrm{Ce}_{1} \mathrm{Zn}_{5}$-e are located at the vertex of the convexhull. The new structure of $\mathrm{Ce}_{1} \mathrm{Zn}_{1}-\mathrm{p}$ and $\mathrm{Ce}_{1} \mathrm{Zn}_{7}-\mathrm{p}$ are also likely to be synthesized since they are also located at the convexhull curve. Moreover, a structure of $\mathrm{Ce}_{1} \mathrm{Zn}_{4}$-p from the search may also be synthesized because its formation energy is very close to the convex-hull curve.

We will point that although extensive efforts have been paid we cannot speculate to find all the possible stable phases of Ce-TM compounds. For some complex phases which include more than sixteen atoms in the primitive cell, and those with too large compositions ( $x$ is too big or too small), we cannot find them from our structural search. Nevertheless, so many lowenergy phases have been discovered which indicates that our structural search method is efficient. Based on these new phases, as well as those already known phases, we can get deeper understanding on the behavior of the Ce $4 \mathrm{f}$ electrons.

\subsection{Structural features}

The space groups and lattice constants of all the predicted phases are summarized in Table 1. For comparison, the measured lattice constants of the experimental phases are also listed. Clearly, the calculated lattice constants are in good agreement with the measured values for the experimental phases.

3.2.1 Ce-Fe. The experimental phases of $\mathrm{Ce}_{1} \mathrm{Fe}_{2}-\mathrm{e}$ and $\mathrm{Ce}_{1} \mathrm{Fe}_{5}$-e possess high symmetries. $\mathrm{Ce}_{1} \mathrm{Fe}_{2}$-e belongs to the cubic crystalline system with the space group of $F d \overline{3} m$ (no. 227). $\mathrm{Ce}_{1} \mathrm{Fe}_{5}-\mathrm{e}$ is a hexagonal crystal whose space group is $P 6 / \mathrm{mmm}$ (no. 191). As shown in Fig. 2, in both structures, the Ce and Fe atoms are highly coordinated, forming very compact structures. Here, the coordination number is counted at the bond-length cutoff of $3.5 \AA$ for Ce-Ce bond, $3.2 \AA$ for Ce-Fe bonds and 3.0 $\AA$ for $\mathrm{Fe}-\mathrm{Fe}$ respectively. The same criteria are used when counting the coordination number for the other Ce-TM compounds. In $\mathrm{Ce}_{1} \mathrm{Fe}_{2}$-e, each Ce atom is in coordination with four Ce atoms and twelve $\mathrm{Fe}$ atoms, while each $\mathrm{Fe}$ atom is in 

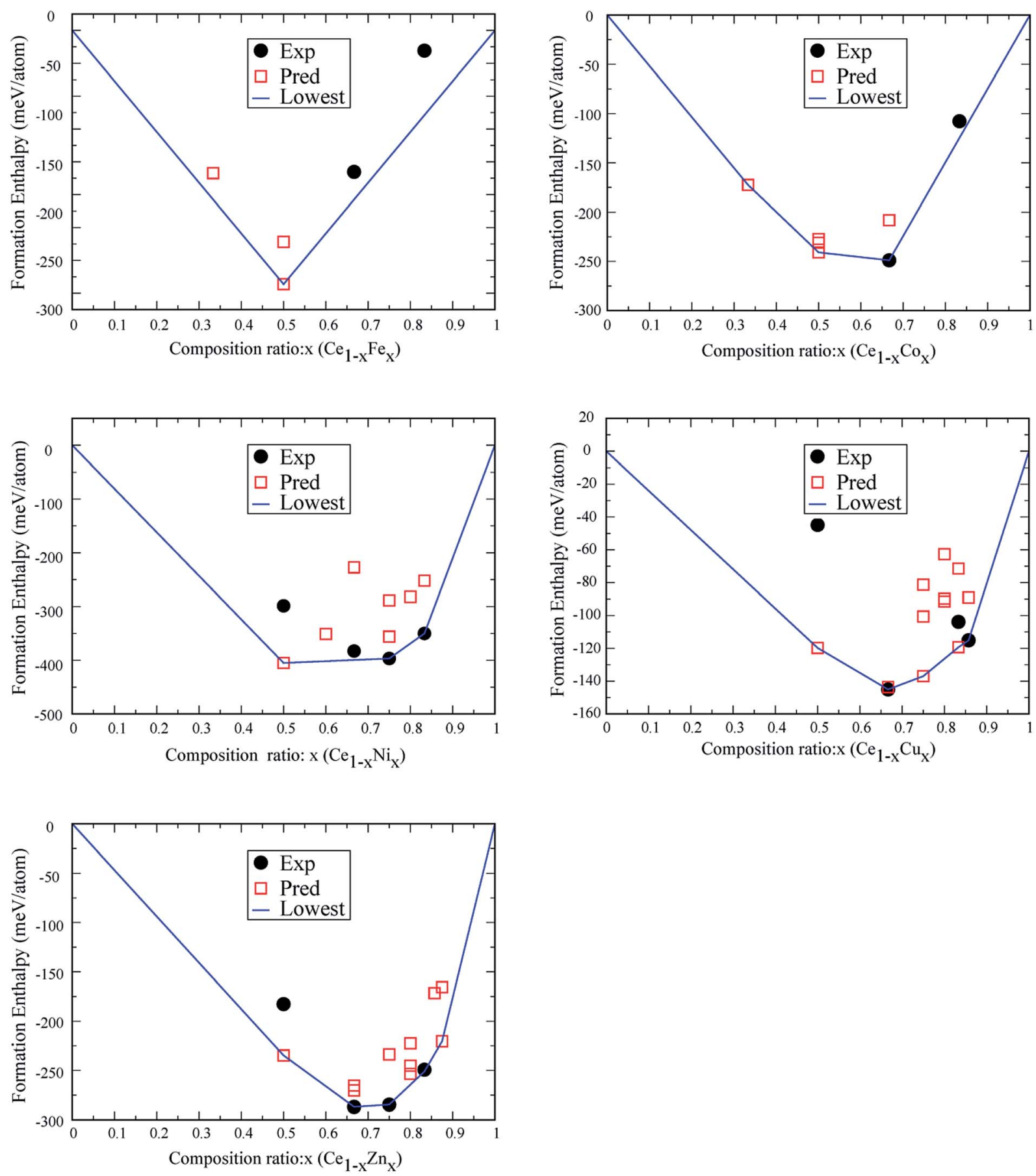

Fig. 1 Convex-hull of formation energies of different Ce-TM binary compounds.

coordination with six $\mathrm{Ce}$ atoms and six $\mathrm{Fe}$ atoms, forming a distorted icosahedron. In $\mathrm{Ce}_{1} \mathrm{Fe}_{5}-\mathrm{e}$, Ce is in coordination with eighteen $\mathrm{Fe}$ atoms, higher than that in $\mathrm{Ce}_{1} \mathrm{Fe}_{2}$-e. $\mathrm{Fe}$ is in coordination with three $\mathrm{Ce}$ atoms and nine $\mathrm{Fe}$ atoms, the same as that in $\mathrm{Ce}_{1} \mathrm{Fe}_{2}$-e. In both phases, $\mathrm{Fe}$ atoms form tetrahedrons. The Fe tetrahedrons connect with each other via sharing the vertex, forming the structural frames. The Ce atoms are inserted into the interstitials of the structural frames.

Structures of the predicted phases $\mathrm{Ce}_{1} \mathrm{Fe}_{1}-\mathrm{p}$ and $\mathrm{Ce}_{2} \mathrm{Fe}_{1}-\mathrm{p}$ are much different from $\mathrm{Ce}_{1} \mathrm{Fe}_{2}$-e and $\mathrm{Ce}_{1} \mathrm{Fe}_{5}$-e. Both structures possess lower symmetries. $\mathrm{Ce}_{2} \mathrm{Fe}_{1}$-p is a monoclinic crystal with the space group of $P 2_{1} / m$ (no. 11) while $\mathrm{Ce}_{1} \mathrm{Fe}_{1}$-p belongs to orthorhombic crystalline system with $\mathrm{Cmcm}$ (no. 63) space group. In $\mathrm{Ce}_{2} \mathrm{Fe}_{1}$-p, there are two nonequivalent Ce atoms in the unit cell. Both are in ten-fold coordination with seven Ce atoms and three $\mathrm{Fe}$ atoms. The coordination number of $\mathrm{Fe}$ is nine, which includes seven Ce atoms and two Fe atoms. Structurally, $\mathrm{Ce}_{2} \mathrm{Fe}_{1}-\mathrm{p}$ can be viewed as Ce bulk with embedded Fe chains. In $\mathrm{Ce}_{1} \mathrm{Fe}_{1}$-p, each Ce atom is in coordination with seven Fe atoms and four Ce atoms, and each Fe atom is in coordination with 
Table 1 The space group, lattice constants, bulk modulus $B$, shear modulus $G$, Pugh ratio $B / G$ for $\mathrm{Ce}-\mathrm{Fe}, \mathrm{Ce}-\mathrm{Co}, \mathrm{Ce}-\mathrm{Ni}, \mathrm{Ce}-\mathrm{Cu}$, and $\mathrm{Ce}-\mathrm{Zn}$ compounds

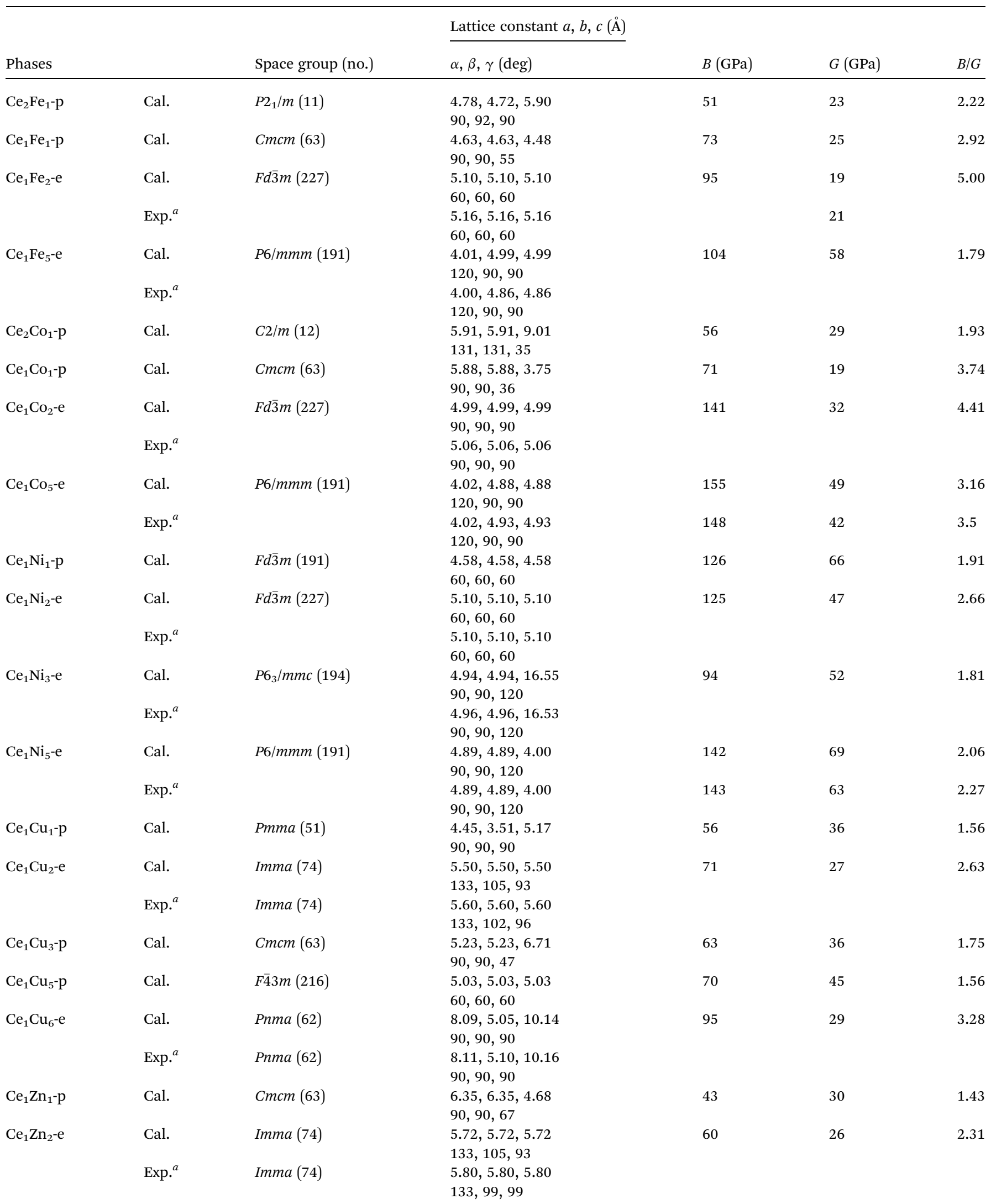


Table 1 (Contd.)

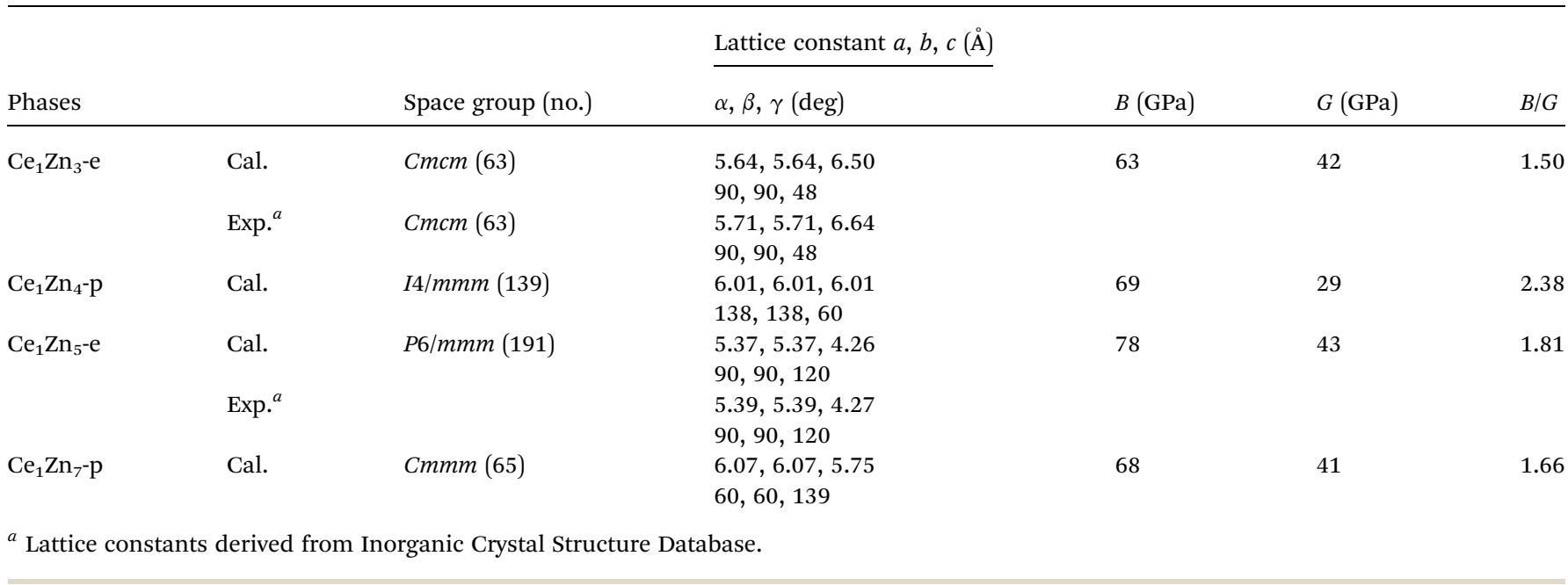

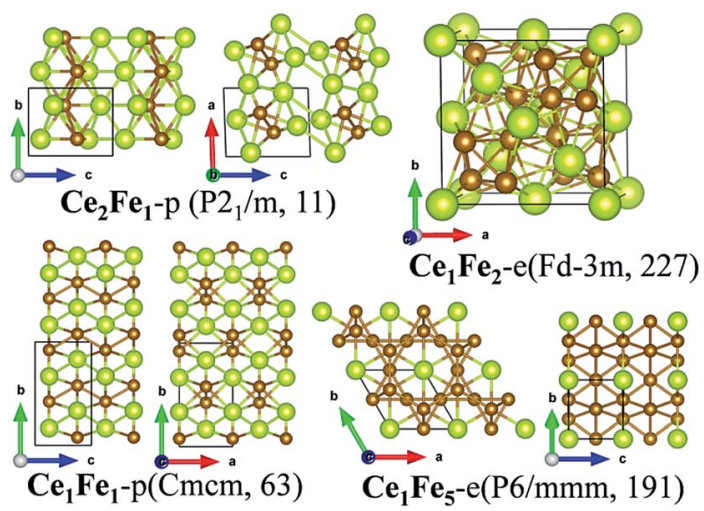

Fig. 2 Crystalline structures of $\mathrm{Ce}_{2} \mathrm{Fe}_{1}-\mathrm{p}, \mathrm{Ce}_{1} \mathrm{Fe}_{1}-\mathrm{p}, \mathrm{Ce}_{1} \mathrm{Fe}_{2}-\mathrm{e}$ and $\mathrm{Ce}_{1} \mathrm{Fe}_{5}-\mathrm{e}$. The new predicted phases are denoted as $\mathrm{Ce}_{m} \mathrm{Fe}_{n}-\mathrm{p}$, while those taken from in experiments are denoted as $\mathrm{Ce}_{m} \mathrm{Fe}_{n}-\mathrm{e}$. And so does for $\mathrm{Ce}-\mathrm{Co}, \mathrm{Ce}-\mathrm{Ni}, \mathrm{Ce}-\mathrm{Cu}$ and $\mathrm{Ce}-\mathrm{Zn}$ compounds.

seven Ce atoms and two Fe atoms. The coordination number of $\mathrm{Ce}$ is a little higher than that in $\mathrm{Ce}_{2} \mathrm{Fe}_{1}$-p while the coordination number of $\mathrm{Fe}$ in both structures is the same. Fe atoms also form Fe chains similar as those in $\mathrm{Ce}_{2} \mathrm{Fe}_{1}$-p. So, $\mathrm{Ce}_{2} \mathrm{Fe}_{1}$-p and $\mathrm{Ce}_{1} \mathrm{Fe}_{1^{-}}$ $\mathrm{p}$ also exhibit some similarity in structures, similar as $\mathrm{Ce}_{1} \mathrm{Fe}_{2}$-e and $\mathrm{Ce}_{1} \mathrm{Fe}_{5}$-e. It seems that the richness of $\mathrm{Fe}$ dominants general structural features of Ce-Fe binary compounds.

3.2.2 Ce-Co. For Ce-Co compounds, stable phases are also found for the composition of $\mathrm{Ce}_{2} \mathrm{Co}_{1}-\mathrm{p}, \mathrm{Ce}_{1} \mathrm{Co}_{1}-\mathrm{p}, \mathrm{Ce}_{1} \mathrm{Co}_{2}-\mathrm{e}$ and $\mathrm{Ce}_{1} \mathrm{Co}_{5}$-e, same as Ce-Fe compounds. The experimental phases of $\mathrm{Ce}_{1} \mathrm{Co}_{2}$-e and $\mathrm{Ce}_{1} \mathrm{Co}_{5}$-e are also the most energetically stable phases for these compositions. Their structures are the same as the corresponding phases of Ce-Fe compounds (see Fig. 3). The structures of the predicted phases of $\mathrm{Ce}_{2} \mathrm{Co}_{1}-\mathrm{p}$ and $\mathrm{Ce}_{1} \mathrm{Co}_{1}-\mathrm{p}$ are similar to those of Ce-Fe compounds with a little difference. $\mathrm{Ce}_{2} \mathrm{Co}_{1}$-p is a monoclinic crystal with the space group of $\mathrm{C} 2 / \mathrm{m}$ (no. 12). Its structure is very loose, compared to $\mathrm{Ce}_{2} \mathrm{Fe}_{1}$-p. The coordination number of $\mathrm{Ce}_{1}, \mathrm{Ce}_{2}$ and $\mathrm{Co}$ is six, seven and seven, respectively, all apparently less than those of $\mathrm{Ce}_{2} \mathrm{Co}_{1}-\mathrm{p}$. The average bond lengths of $\mathrm{Ce}-\mathrm{Ce}$ and $\mathrm{Ce}-\mathrm{Co}$ in $\mathrm{Ce}_{2} \mathrm{Co}_{1}-\mathrm{p}$ are longer than those in $\mathrm{Ce}_{1} \mathrm{Co}_{2}$-e. The structure of $\mathrm{Ce}_{1} \mathrm{Co}_{1}$-p is similar to that of $\mathrm{Ce}_{1} \mathrm{Fe}_{1}-\mathrm{p}$. Compared to $\mathrm{Ce}_{1} \mathrm{Fe}_{1}-\mathrm{p}$, the structure of $\mathrm{Ce}_{1} \mathrm{Co}_{1}$-p is elongated along the crystal basis vector $\vec{b}$, causing decreased $\mathrm{Ce}-\mathrm{Ce}$ bonds and $\mathrm{Ce}-\mathrm{Co}$ bonds. So, in $\mathrm{Ce}_{1} \mathrm{Co}_{1}-\mathrm{p}$, the coordination number of $\mathrm{Ce}$ and $\mathrm{Co}$ is seven and nine, respectively, less than those in $\mathrm{Ce}_{1} \mathrm{Fe}_{1}$-p as well.

3.2.3 Ce-Ni. For the four stable phases of Ce-Ni binary compounds, the experimental structures of $\mathrm{Ce}_{1} \mathrm{Ni}_{2}-\mathrm{e}$ and $\mathrm{Ce}_{1} \mathrm{Ni}_{5}$-e are the same as those of Ce-Fe and Ce-Co compounds (see Fig. 4). The experimental structure $\mathrm{Ce}_{1} \mathrm{Ni}_{3}$-e possesses a hexagonal lattice with the space group of $P 6_{3} / m m c$ (no. 194). There are two nonequivalent Ce atoms (denoted as $\mathrm{Ce}_{1}$ and $\mathrm{Ce}_{2}$ respectively) and four nonequivalent $\mathrm{Ni}$ atoms in each unit cell, respectively. The first Ce atom $\left(\mathrm{Ce}_{1}\right)$ is located at the center of a hexagonal ring of six $\mathrm{Ni}$ atoms. Besides the six $\mathrm{Ni}$ atoms, $\mathrm{Ce}_{1}$ is bonded with two $\mathrm{Ce}_{2}$ atoms located directly above and below $\mathrm{Ce}_{1}$. So the coordination number of $\mathrm{Ce}_{1}$ is eight. $\mathrm{Ce}_{2}$ is bonded with one $\mathrm{Ce}_{1}$ atom, three $\mathrm{Ce}_{2}$ atoms and twelve $\mathrm{Ni}$ atoms, respectively, and has a high coordination number of sixteen. For Ni atoms, the coordination number of three of them is twelve, while that of others is ten.

The structure of the predicted phases $\mathrm{Ce}_{1} \mathrm{Ni}_{1}-\mathrm{p}$ is much different from the experimental one and possesses much lower energy. $\mathrm{Ce}_{1} \mathrm{Ni}_{1}$-p has a cubic lattice with the space group of $F d \overline{3} m$ (no. 227). Each Ce or Ni atom is located at the center of a cubic whose vertices are occupied by four Ce or four Ni atoms,

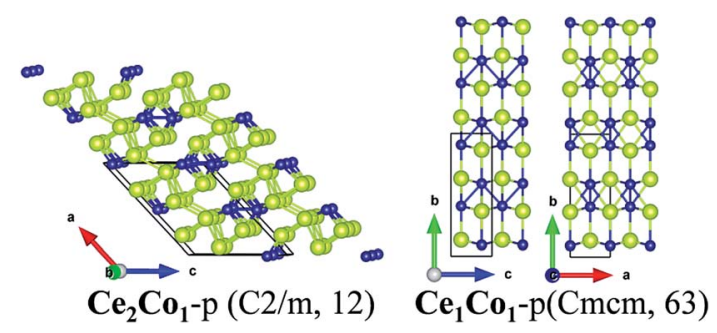

Fig. 3 Crystalline structures of $\mathrm{Ce}_{2} \mathrm{Co}_{1}-\mathrm{p}$ and $\mathrm{Ce}_{1} \mathrm{Co}_{1}-\mathrm{p}$. 


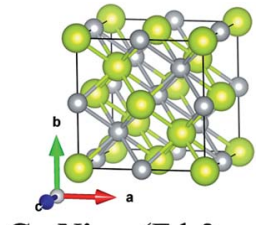

$\mathrm{Ce}_{\mathbf{1}} \mathbf{N i}_{\mathbf{1}}$-p (Fd-3m, 227)

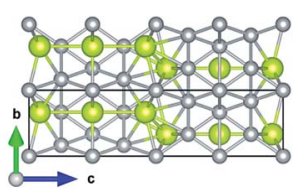

$\mathrm{Ce}_{1} \mathrm{Ni}_{3}$-e $\left(\mathrm{P6}_{3} / \mathrm{mmc}, 194\right)$

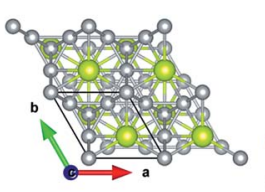

Fig. 4 Crystalline structures of $\mathrm{Ce}_{1} \mathrm{Ni}_{1}-\mathrm{p}$ and $\mathrm{Ce}_{1} \mathrm{Ni}_{3}-\mathrm{e}$.

respectively. The four Ce atoms at the cubic vertices form regular tetrahedron, and so do the four $\mathrm{Ni}$ atoms. Thus, both $\mathrm{Ce}$ and $\mathrm{Ni}$ are in eight-fold coordination.

3.2.4 $\mathrm{Ce}-\mathrm{Cu}$. For $\mathrm{Ce}-\mathrm{Cu}$ binary compounds, four experimental phases are reported, namely, $\mathrm{Ce}_{1} \mathrm{Cu}_{1}-\mathrm{e}, \mathrm{Ce}_{1} \mathrm{Cu}_{2}-\mathrm{e}$, $\mathrm{Ce}_{1} \mathrm{Cu}_{5}$-e and $\mathrm{Ce}_{1} \mathrm{Cu}_{6}$-e. $\mathrm{Ce}_{1} \mathrm{Cu}_{2}$-e and $\mathrm{Ce}_{1} \mathrm{Cu}_{6}$-e are the most energetically stable phases of their compositions, based on our calculation. However, $\mathrm{Ce}_{1} \mathrm{Cu}_{1}$-e and $\mathrm{Ce}_{1} \mathrm{Cu}_{5}$-e are only metastable because a new phase with much lower formation enthalpy for each composition is found from our unbiased search. The structure of $\mathrm{Ce}_{1} \mathrm{Cu}_{5}-\mathrm{e}$ is the same as that of $\mathrm{Ce}_{1} \mathrm{Fe}_{5}-\mathrm{e}$, $\mathrm{Ce}_{1} \mathrm{Co}_{5}$-e and $\mathrm{Ce}_{1} \mathrm{Ni}_{5}$-e. No stable phases are found for $\mathrm{Ce}_{1} \mathrm{TM}_{6}$ for other transition metals. Although $\mathrm{Ce}_{1} \mathrm{Cu}_{2}$-e is still very stable, its structure is much different from those of $\mathrm{Ce}_{1} \mathrm{Fe}_{2}-\mathrm{e}$, $\mathrm{Ce}_{1} \mathrm{Co}_{2}$-e and $\mathrm{Ce}_{1} \mathrm{Ni}_{2}$-e. As shown in Fig. $5, \mathrm{Ce}_{1} \mathrm{Cu}_{2}$-e possesses an orthorhombic lattice and belongs to Imma (no. 74) space group, while $\mathrm{Ce}_{1} \mathrm{Fe}_{2}-\mathrm{e}, \mathrm{Ce}_{1} \mathrm{Co}_{2}$-e and $\mathrm{Ce}_{1} \mathrm{Ni}_{2}$-e are all cubic crystals with space group of $F d \overline{3} m$ (no. 227). $\mathrm{Ce}_{1} \mathrm{Cu}_{2}$-e can be viewed as constructed by inserting Ce atoms between buckled $\mathrm{Cu}$ honeycomb slabs. Ce atoms are located directly above the center of all the hexagonal rings. The coordination number of $\mathrm{Ce}$ and $\mathrm{Cu}$ in $\mathrm{Ce}_{1} \mathrm{Ni}_{2}$-e is 14 and 10, respectively, both being a little less than that in $\mathrm{Ce}_{1} \mathrm{Fe}_{2}-\mathrm{e}, \mathrm{Ce}_{1} \mathrm{Co}_{2}$-e and $\mathrm{Ce}_{1} \mathrm{Ni}_{2}$-e.

For the predicted phases, $\mathrm{Ce}_{1} \mathrm{Cu}_{1}-\mathrm{p}$ possesses an orthorhombic crystalline lattice with space group of Pmma (no. 51). Both $\mathrm{Ce}$ and $\mathrm{Cu}$ atoms form zig-zag atomic chains, respectively. Each Ce atomic chain connects with four $\mathrm{Cu}$ atomic chains, and vice versa. Each $\mathrm{Ce}$ atom is in coordination with six $\mathrm{Cu}$ atoms and two Ce atoms, and each $\mathrm{Cu}$ atom is in coordination with six
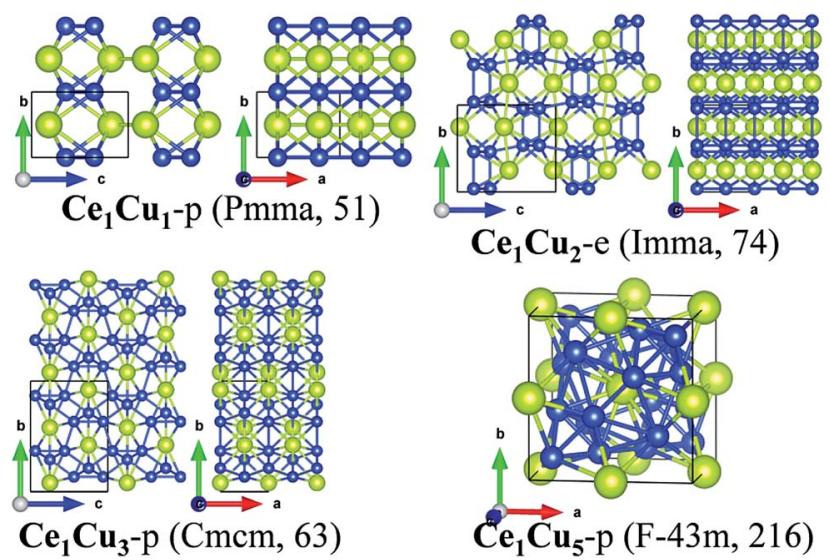

Fig. 5 Crystalline structures of $\mathrm{Ce}_{1} \mathrm{Cu}_{1}-\mathrm{p}, \mathrm{Ce}_{1} \mathrm{Cu}_{2}-\mathrm{e}, \mathrm{Ce}_{1} \mathrm{Cu}_{3}-\mathrm{p}$ and $\mathrm{Ce}_{1} \mathrm{Cu}_{5}-\mathrm{p}$.
$\mathrm{Ce}$ atoms and two $\mathrm{Cu}$ atoms. So the coordination number of them is eight. $\mathrm{Ce}_{1} \mathrm{Cu}_{5}$-p is a cubic crystal with the space group of Fī3m (no. 216). In the conventional cell, there are one Ce atom located at the center of the cube and one Ce atom located at the center of each side of the cube, respectively. The $\mathrm{Cu}$ atoms form a face-capped pyramid structure with the Ce atom at the center. The four vertexes of the pyramid point to the four non-nearestneighbor corners of the cube to keep the $T_{\mathrm{d}}$ rotation symmetry of the structure. The central Ce atom is bonded with all the $\mathrm{Cu}$ atoms of the face-capped pyramid except the four corner ones. Thus its coordination number is 16 . The $16 \mathrm{Cu}$ atoms coordinated with the Ce atom form a polyhedron with 28 faces. There are 4 hexagons and 12 pentagons in this 28 -faces polyhedron. Each $\mathrm{Cu}$ atom is in 12-fold coordination, giving a distorted icosahedron with the surrounded atoms. The local structure of $\mathrm{Ce}_{1} \mathrm{Cu}_{5}-\mathrm{p}$ is a little similar to those of $\mathrm{Ce}_{1} \mathrm{Fe}_{2}-\mathrm{e}, \mathrm{Ce}_{1} \mathrm{Co}_{2}$-e and $\mathrm{Ce}_{1} \mathrm{Ni}_{2}$-e, where the 28-faces polyhedron and icosahedron are also formed with the center of $\mathrm{Ce}$ and the transition atom respectively.

3.2.5 Ce-Zn. For Ce-Zn binary compounds, four phases are

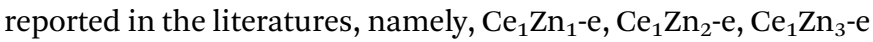
and $\mathrm{Ce}_{1} Z_{n_{5}}-\mathrm{e}$. According to our calculation, $\mathrm{Ce}_{1} Z_{2}-\mathrm{e}, \mathrm{Ce}_{1} \mathrm{Zn}_{3}-\mathrm{e}$ and $\mathrm{Ce}_{1} \mathrm{Zn}_{5}$-e are indeed the most energetically stable structures of the corresponding compositions, while $\mathrm{Ce}_{1} \mathrm{Zn}_{1}$-e is not. The structure of $\mathrm{Ce}_{1} \mathrm{Zn}_{5}$-e is the same as those of $\mathrm{Ce}_{1} \mathrm{Fe}_{5}-\mathrm{e}, \mathrm{Ce}_{1} \mathrm{Co}_{5}-\mathrm{e}$, $\mathrm{Ce}_{1} \mathrm{Ni}_{5}$-e and $\mathrm{Ce}_{1} \mathrm{Cu}_{5}$-e. $\mathrm{Ce}_{1} \mathrm{Zn}_{2}$-e is very similar to that of $\mathrm{Ce}_{1} \mathrm{Cu}_{2}$-e (Fig. 6). Both structures have the same space group of Imma (no. 74). Zn atoms form buckled single-layer honeycomb slabs as $\mathrm{Cu}$ atoms do in $\mathrm{Ce}_{1} \mathrm{Cu}_{2}$-e. Ce atoms are located above the center of each hexagonal ring. The buckling of $\mathrm{Zn}$ honeycomb slabs is more dramatic than that of the $\mathrm{Cu}$ honeycomb slabs in $\mathrm{Ce}_{1} \mathrm{Cu}_{2}-\mathrm{e}$, due to the shorter $\mathrm{Zn}-\mathrm{Zn}$ bonds connecting adjacent bucking $\mathrm{Zn}$ honeycomb slabs. $\mathrm{Ce}_{1} \mathrm{Zn}_{3}$-e has the same space group as $\mathrm{Ce}_{1} \mathrm{Cu}_{3}$-p. After checking the detailed structures
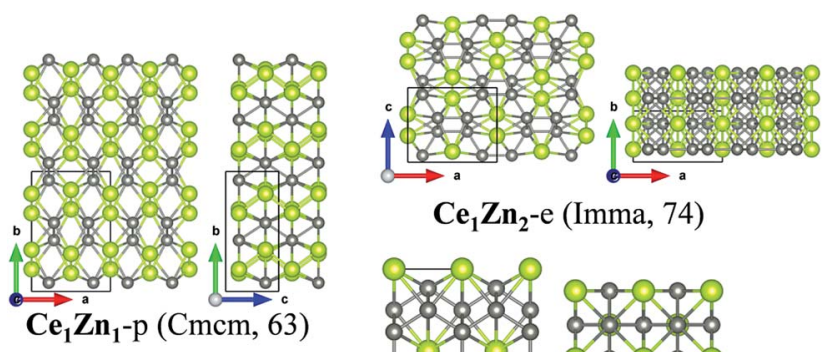

$$
\mathrm{Ce}_{1} \mathrm{Zn}_{2} \text {-e (Imma, 74) }
$$
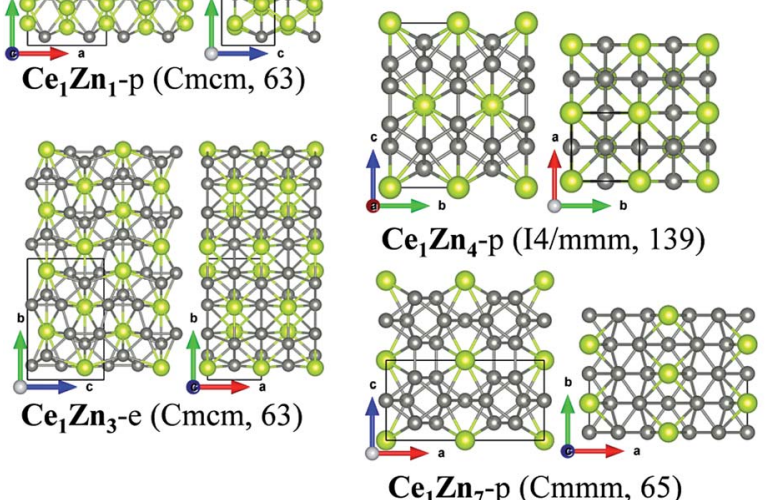

Fig. 6 Crystalline structures of $C e_{1} Z n_{1}-p, C e_{1} Z n_{2}-e, C e_{1} Z n_{3}-e$, $\mathrm{Ce}_{1} Z \mathrm{n}_{4}-\mathrm{p}$ and $\mathrm{Ce}_{1} Z \mathrm{nn}_{7}-\mathrm{p}$. 
of $\mathrm{Ce}_{1} \mathrm{Zn}_{3}$-e and $\mathrm{Ce}_{1} \mathrm{Cu}_{3}$-p, we find that they are almost the same. The success of the synthesis of $\mathrm{Ce}_{1} \mathrm{Zn}_{3}$-e implies that the synthesis of $\mathrm{Ce}_{1} \mathrm{Cu}_{3}-\mathrm{p}$ is also possible to be synthesized by experiment.

For the predicted phases, the structure of $\mathrm{Ce}_{1} \mathrm{Zn}_{1}-\mathrm{p}$ is the same as that of $\mathrm{Ce}_{1} \mathrm{Fe}_{1}$-p and is similar to that of $\mathrm{Ce}_{1} \mathrm{Co}_{1}$-p. $\mathrm{Ce}_{1} \mathrm{Zn}_{4}-\mathrm{p}$ is metastable according to the computed formation energy. It is a tetragonal crystal with the space group of $I 4 / \mathrm{mmm}$ (no. 139). Each Ce atom is encapsulated by a cage constructed by $18 \mathrm{Zn}$ atoms. The four sides of the $\mathrm{Zn}$ cage are all hexagonal rings, while the two roofs are both constructed by four rhombic rings. The coordination number of $\mathrm{Ce}$ is 16 and that of $\mathrm{Zn}$ is 8 . $\mathrm{Ce}_{1} \mathrm{Zn}_{7}-\mathrm{p}$ possesses an orthorhombic crystalline structure and the space group of $\mathrm{Cmmm}$ (no. 65). Its structure is much more complicated because there are more atoms included in one conventional unit cell. All the Ce atoms are equivalent in crystallography, while there are three nonequivalent $\mathrm{Zn}$ atoms. Each Ce atom is in coordination with $12 \mathrm{Zn}$ atoms. $\mathrm{Zn}_{1}, \mathrm{Zn}_{2}$, and $\mathrm{Zn}_{3}$ have a coordination number of 9,8 and 10 , respectively.

\subsection{Electronic properties}

The diverse physical properties such as heavy-fermion, Kondolattice, and intermediate-valence effects of Ce-based binary compounds are highly correlated with the behavior of the $4 \mathrm{f}$ electrons in Ce. For the Ce-TM binary compounds, the $3 \mathrm{~d}$ electrons of the TM elements may also affect their properties. To compute their electronic structures, various initial arrangements of magnetic moments, such as the ferromagnetic, antiferromagnetic, were considered for each structure and the spinpolarized (SP) calculations were performed for each magnetic configuration. We also carried out a non-spin-polarized (NSP) for each structure to compute the energy of a spin-degenerate nonmagnetic phase. The optimized stable magnetic configurations, the magnetic moment on each atom, and the relative energy per atom of the ferro- or antiferro-magnetic configurations compared to that of the spin-degenerate nonmagnetic state of each structure, are all listed in Table 2. To gain deeper insight into the electronic and magnetic structures, the projected density of state (PDOS) of each phase is calculated, as shown in Fig. S2-S6 (see the ESI $\dagger$ ).

From the computed PDOS, we can see that there is obvious hybridization between the $3 \mathrm{~d}$ states of the TM elements and the $4 \mathrm{f}$ and $5 \mathrm{~d}$ states of $\mathrm{Ce}$ atoms for the $\mathrm{Ce}-\mathrm{Fe}, \mathrm{Ce}-\mathrm{Co}$ and $\mathrm{Ce}-\mathrm{Ni}$ binary compounds, while that for the Ce- $\mathrm{Cu}$ and $\mathrm{Ce}-\mathrm{Zn}$ binary compounds is much weaker. Due to the strong hybridization, the distribution of the Ce $4 \mathrm{f}$ states is apparently broadened for $\mathrm{Ce}-\mathrm{Fe}, \mathrm{Ce}-\mathrm{Co}$ and $\mathrm{Ce}-\mathrm{Ni}$ compounds. For some phases, the Ce 4f states distribute in very large energy windows ( 3 to $4 \mathrm{eV}$ ) below the Fermi level, which means that some $4 \mathrm{f}$ electrons of $\mathrm{Ce}$ become itinerant, i.e. the Ce atoms may adopt intermediate valence states in these phases. For the $\mathrm{Ce}-\mathrm{Cu}, \mathrm{Ce}-\mathrm{Zn}$ systems, the close-shell features of the $3 \mathrm{~d}$ orbitals of $\mathrm{Cu}$ and $\mathrm{Zn}$ render them far away from the $4 \mathrm{f}$ orbitals of Ce. Hence, there is little hybridization between them. As shown in Fig. S5 and S6, $\dagger$ the density of the $4 \mathrm{f}$ states of $\mathrm{Ce}$ in the $\mathrm{Ce}-\mathrm{Cu}$ and $\mathrm{Ce}-\mathrm{Zn}$ compounds is quite localized, and is crossed by $E_{\mathrm{F}}$ in their lower part, indicating that the lower $4 \mathrm{f}$ bands are filling by electrons. In almost all the phases of $\mathrm{Ce}-\mathrm{Cu}$ and $\mathrm{Ce}-\mathrm{Zn}$ systems, the $\mathrm{Ce}$ atoms adopt trivalent states.

Moreover, as shown in Fig. S2-S6, $\dagger$ spin splitting occurs for some phases e.g. $\mathrm{Ce}_{1} \mathrm{Fe}_{2}-\mathrm{e}, \mathrm{Ce}_{1} \mathrm{Fe}_{5}-\mathrm{e}, \mathrm{Ce}_{1} \mathrm{Co}_{5}-\mathrm{e}, \mathrm{Ce}_{1} \mathrm{Ni}_{5}-\mathrm{e}$, etc. suggesting that particular magnetic orderings are energetically favored in these phases. We will discuss these ordered magnetic states in details in the following subsections.

3.3.1 Ce-Fe. First, we compare our results with the experimental measurements or previous theoretical calculations. Previous experiment ${ }^{50}$ and theoretical calculation ${ }^{43}$ have shown that $\mathrm{Ce}_{1} \mathrm{Fe}_{2}$-e possesses an ferromagnetic configuration in which the magnetic moments of all the Fe atoms are in the same direction (so do the Ce atoms), while the direction of magnetic moments of the Ce atoms is opposite to that on the $\mathrm{Fe}$ atoms. To obtain the ground magnetic state of $\mathrm{Ce}_{1} \mathrm{Fe}_{2}$-e, we consider five different initial spin arrangements $($ i.e. $\uparrow \uparrow \cdot \uparrow \uparrow \uparrow \uparrow$, $\downarrow \downarrow \cdot \uparrow \uparrow \uparrow \uparrow, \uparrow \downarrow \cdot \downarrow \downarrow \downarrow \downarrow, \uparrow \uparrow \cdot \uparrow \downarrow \uparrow \downarrow, \uparrow \downarrow \cdot \uparrow \downarrow \uparrow \downarrow)$ in spin-polarized calculation and non-spin-polarized calculation to simulate the spin-degenerate nonmagnetic state. The initial magnetic moments on $\mathrm{Ce}$ and $\mathrm{Fe}$ are both $4 \mu_{\mathrm{B}}$, and so do for the other compounds. After structural and electronic relaxation, two magnetic configurations are stable and listed in Table 2. The ground magnetic state is $\downarrow \downarrow \cdot \uparrow \uparrow \uparrow \uparrow$, consistent with previous experimental and theoretical results. The next energetically stable magnetic state is $\downarrow \downarrow \cdot \uparrow \downarrow \uparrow \downarrow$, i.e. the moments on the Fe atoms are aligned anti-ferromagnetically while magnetic moments on Ce atoms adopt the same direction. The highest energy state is the nonmagnetic state. The relative energies of the ground state and the first excited state with respect to the nonmagnetic state are $-94 \mathrm{meV}$ per atom and $-27 \mathrm{meV}$ per atom, respectively. The large energy difference between the ferromagnetic state and the nonmagnetic state indicates that the ferromagnetic state of $\mathrm{Ce}_{1} \mathrm{Fe}_{2}$-e is quite stable.

From the computed projected magnetic moments, we can see that in the ground magnetic state of $\mathrm{Ce}_{1} \mathrm{Fe}_{2}$-e, the magnetic moment $\left(1.76 \mu_{\mathrm{B}}\right)$ of $\mathrm{Fe}$ atoms is almost entirely originated from the $3 \mathrm{~d}$ states, whereas that of Ce atoms is originated from both 4f $\left(-0.58 \mu_{\mathrm{B}}\right)$ states and $5 \mathrm{~d}\left(-0.23 \mu_{\mathrm{B}}\right)$ states. From the PDOS shown in Fig. S2, $\uparrow$ we can see that almost all of the spin-up Fe $3 \mathrm{~d}$ states are distributed below the Fermi level, meaning that they are almost full-filled, while the spin-down $\mathrm{Fe} 3 \mathrm{~d}$ states distribute a little higher and some of them are located above the Fermi level. Thus, the net magnetic moments on Fe atoms are aligned upward. Moreover, because the overlapping of the spindown Fe $3 \mathrm{~d}$ states with the Ce $4 \mathrm{f}$ and $5 \mathrm{~d}$ states, there is strong hybridization between them, which results in more Ce $4 \mathrm{f}$ and $5 \mathrm{~d}$ electrons occupying the spin-down states. So the net magnetic moments on Ce atoms are aligned opposite to those on $\mathrm{Fe}$ atoms.

For the $\mathrm{Ce}_{1} \mathrm{Fe}_{5}-\mathrm{e}$, spin-polarized computations with ten initial magnetic configurations (i.e. $\uparrow \cdot \uparrow \uparrow \uparrow \uparrow \uparrow, \uparrow \cdot \downarrow \uparrow \uparrow \uparrow \uparrow, \downarrow \cdot \downarrow$ $\uparrow \uparrow \uparrow \uparrow, \uparrow \cdot \uparrow \downarrow \uparrow \uparrow \uparrow, \uparrow \cdot \downarrow \downarrow \uparrow \uparrow \uparrow, \downarrow \cdot \downarrow \downarrow \uparrow \uparrow \uparrow, \uparrow \cdot \uparrow \downarrow \downarrow \uparrow \uparrow, \uparrow \cdot \downarrow \downarrow \downarrow$ $\uparrow \uparrow, \downarrow \cdot \downarrow \downarrow \downarrow \uparrow \uparrow, \downarrow \cdot \uparrow \downarrow \uparrow \uparrow \downarrow)$, and non-spin-polarized calculation are performed. Three differently ordered magnetic configurations are found to be stable after relaxation. The most stable magnetic configuration is still ferromagnetic $(\downarrow \cdot \uparrow \uparrow \uparrow \uparrow \uparrow)$, as 
Table 2 Magnetic properties of $\mathrm{Ce}-\mathrm{Fe}, \mathrm{Ce}-\mathrm{Co}, \mathrm{Ce}-\mathrm{Ni}, \mathrm{Ce}-\mathrm{Cu}$, and $\mathrm{Ce}-\mathrm{Zn}$ compounds. The $\uparrow, \downarrow$ and $\mathrm{O}$ represent the positive, negative and zero magnetic moment, respectively. The signs $(\uparrow, \uparrow$ or $\mathrm{O})$ before and behind the dot represent the directions of the magnetic moments on Ce and $\mathrm{TM}(\mathrm{TM}=\mathrm{Fe}, \mathrm{Co}, \mathrm{Ni})$ atoms respectively. For the $\mathrm{Ce}-\mathrm{Cu}$ and $\mathrm{Ce}-\mathrm{Zn}$ compounds, the signs for $\mathrm{Cu}$ or $\mathrm{Zn}$ are omitted since the magnetic moment on $\mathrm{Cu}$ or $\mathrm{Zn}$ is always zero. The relative energies $\Delta E$ (in meV per atom) of magnetic ordering state compared to that of the spindegenerate nonmagnetic state are also calculated and shown in the table

\begin{tabular}{|c|c|c|c|}
\hline Phase & Ground magnetic state & First excited magnetic state & Second excited magnetic state \\
\hline $\mathrm{Ce}_{2} \mathrm{Fe}_{1}-\mathrm{p}$ & Nonmagnetic & & \\
\hline $\mathrm{Ce}_{1} \mathrm{Fe}_{1}-\mathrm{p}$ & Nonmagnetic & & \\
\hline \multirow{3}{*}{$\mathrm{Ce}_{1} \mathrm{Fe}_{2}-\mathrm{e}$} & $\downarrow \downarrow \cdot \uparrow \uparrow \uparrow \uparrow$ & $\downarrow \downarrow \cdot \uparrow \downarrow \uparrow \downarrow$ & Nonmagnetic \\
\hline & Ce: -0.83 & Ce: -0.33 & \\
\hline & Fe: 1.76 & Fe: $1.45(-0.22)$ & \\
\hline$\Delta E$ & -94 & -27 & \\
\hline \multirow[t]{3}{*}{$\mathrm{Ce}_{1} \mathrm{Fe}_{5}-\mathrm{e}$} & $\downarrow \cdot \uparrow \uparrow \uparrow \uparrow \uparrow$ & $\downarrow \cdot \downarrow \uparrow \uparrow \uparrow \uparrow$ & $\uparrow \cdot \downarrow \downarrow \downarrow \uparrow \uparrow$ \\
\hline & Ce: -0.61 & Ce: -0.38 & Ce: 0.17 \\
\hline & Fe: 2.12 & Fe: $-0.88(1.97)$ & Fe: $-1.78(1.40)$ \\
\hline$\Delta E$ & -203 & -110 & -97 \\
\hline $\mathrm{Ce}_{2} \mathrm{Co}_{1}-\mathrm{p}$ & Nonmagnetic & & \\
\hline $\mathrm{Ce}_{1} \mathrm{Co}_{1}-\mathrm{p}$ & Nonmagnetic & & \\
\hline $\mathrm{Ce}_{1} \mathrm{Co}_{2}-\mathrm{e}$ & Nonmagnetic & & \\
\hline \multirow[t]{3}{*}{$\mathrm{Ce}_{1} \mathrm{Co}_{5}-\mathrm{e}$} & $\downarrow \cdot \uparrow \uparrow \uparrow \uparrow \uparrow$ & $\mathrm{O} \cdot \uparrow \downarrow \mathrm{OOO}$ & Nonmagnetic \\
\hline & Ce: -0.74 & Ce: 0.0 & \\
\hline & Co: 1.40 & $\mathrm{Co}_{1}: 0.55(-0.55) ; \mathrm{Co}_{2}: 0.0$ & \\
\hline$\Delta E$ & -69 & -1 & \\
\hline $\mathrm{Ce}_{1} \mathrm{Ni}_{1}-\mathrm{p}$ & Nonmagnetic & & \\
\hline $\mathrm{Ce}_{1} \mathrm{Ni}_{2}-\mathrm{e}$ & Nonmagnetic & & \\
\hline $\mathrm{Ce}_{1} \mathrm{Ni}_{3}-\mathrm{e}$ & Nonmagnetic & & \\
\hline \multirow[t]{3}{*}{$\mathrm{Ce}_{1} \mathrm{Ni}_{5}-\mathrm{e}$} & $\downarrow \cdot \uparrow \uparrow \uparrow \uparrow \uparrow$ & Nonmagnetic & \\
\hline & Ce: -0.23 & & \\
\hline & $\mathrm{Ni}_{1}: 0.18 ; \mathrm{Ni}_{2}: 0.26$ & & \\
\hline$\Delta E$ & -3 & & \\
\hline $\mathrm{Ce}_{1} \mathrm{Cu}_{1}-\mathrm{p}$ & Nonmagnetic & & \\
\hline \multirow[t]{2}{*}{$\mathrm{Ce}_{1} \mathrm{Cu}_{2}-\mathrm{e}$} & $\uparrow \downarrow$ & Nonmagnetic & \\
\hline & Ce: $0.08(-0.08)$ & & \\
\hline$\Delta E$ & -2 & & \\
\hline \multirow{2}{*}{$\mathrm{Ce}_{1} \mathrm{Cu}_{3}-\mathrm{p}$} & $\downarrow \downarrow$ & Nonmagnetic & \\
\hline & Ce: -0.23 & & \\
\hline$\Delta E$ & -0.07 & & \\
\hline \multirow[t]{2}{*}{$\mathrm{Ce}_{1} \mathrm{Cu}_{5}-\mathrm{p}$} & $\downarrow$ & Nonmagnetic & \\
\hline & Ce: -0.21 & & \\
\hline$\Delta E$ & -0.1 & & \\
\hline \multirow[t]{2}{*}{$\mathrm{Ce}_{1} \mathrm{Cu}_{6}-\mathrm{e}$} & $\downarrow \downarrow \downarrow \downarrow$ & $\downarrow \uparrow \uparrow \uparrow$ & $\downarrow \downarrow \uparrow \uparrow$ \\
\hline & Ce: -0.33 & Ce: $-0.13(0.27)$ & Ce: $0.23(-0.23)$ \\
\hline$\Delta E$ & -0.18 & -0.02 & -0.00 \\
\hline $\mathrm{Ce}_{1} \mathrm{Zn}_{1}-\mathrm{p}$ & Nonmagnetic & & \\
\hline \multirow[t]{3}{*}{$\mathrm{Ce}_{1} \mathrm{Zn}_{2}-\mathrm{e}$} & $\uparrow \uparrow$ & $\uparrow \downarrow$ & Nonmagnetic \\
\hline & Ce: 0.65 & Ce: $0.42(-0.42)$ & \\
\hline & -6.8 & -0.5 & \\
\hline \multirow[t]{2}{*}{$\mathrm{Ce}_{1} \mathrm{Zn}_{3}-\mathrm{e}$} & $\uparrow \downarrow$ & Nonmagnetic & \\
\hline & Ce: $0.34(-0.34)$ & & \\
\hline$\Delta E$ & -1 & & \\
\hline \multirow[t]{2}{*}{$\mathrm{Ce}_{1} \mathrm{Zn}_{4}-\mathrm{p}$} & $\uparrow$ & Nonmagnetic & \\
\hline & Ce: 0.64 & & \\
\hline$\Delta E$ & -3 & & \\
\hline \multirow[t]{2}{*}{$\mathrm{Ce}_{1} \mathrm{Zn}_{5}-\mathrm{e}$} & $\uparrow$ & Nonmagnetic & \\
\hline & Ce: 0.73 & & \\
\hline$\Delta E$ & -3 & & \\
\hline \multirow[t]{2}{*}{$\mathrm{Ce}_{1} \mathrm{Zn}_{7}-\mathrm{p}$} & $\uparrow$ & Nonmagnetic & \\
\hline & Ce: 0.63 & & \\
\hline$\Delta E$ & -2 & & \\
\hline
\end{tabular}

that of $\mathrm{Ce}_{1} \mathrm{Fe}_{2}$-e. The magnetic moments on Ce atoms are $-0.61 \mu_{\mathrm{B}}$ and those on $\mathrm{Fe}$ atoms are $2.12 \mu_{\mathrm{B}}$. The magnetic moments on Ce are also contributed by both Ce $4 \mathrm{f}$ and $5 \mathrm{~d}$ electrons. As shown in Fig. $\mathrm{S} 2, \uparrow$ similar to $\mathrm{Ce}_{1} \mathrm{Fe}_{2}$-e, the reason for the magnetic moments on Ce atoms is the strong hybridization between the Fe $3 \mathrm{~d}$ and $\mathrm{Ce} 4 \mathrm{f}$ and $5 \mathrm{~d}$ states due to the large splitting of the $3 \mathrm{~d}$ spin-up and spin-down states. The energy difference between the ferromagnetic state and the 
nonmagnetic state is $-203 \mathrm{meV}$ per atom. Hence, the ferromagnetic state is quite stable. Besides the ferromagnetic state, two magnetic states, i.e. $\downarrow \cdot \downarrow \uparrow \uparrow \uparrow \uparrow$ and $\mathrm{O} \cdot \downarrow \downarrow \downarrow \uparrow \uparrow$ are metastable with the energy differences of $-110 \mathrm{meV}$ per atom and $-97 \mathrm{meV}$ per atom with respect to the nonmagnetic state, respectively. Because of the large energy difference, the two magnetic states are also stable.

For the two predicted Ce-Fe phases, $\mathrm{Ce}_{2} \mathrm{Fe}_{1}-\mathrm{p}$ and $\mathrm{Ce}_{1} \mathrm{Fe}_{1}-\mathrm{p}$, although various initial magnetic configurations are considered, all of them converge into the nonmagnetic state. It is known that with the large positive value of the exchange interaction $J$ between Fe atoms, bulk $\mathrm{Fe}$ and Fe-rich alloys tend to exhibit ferromagnetic properties. As discussed above, for the Ferich $\mathrm{Ce}-\mathrm{Fe}$ phases $\left(\mathrm{Ce}_{1} \mathrm{Fe}_{2}\right.$-e and $\left.\mathrm{Ce}_{1} \mathrm{Fe}_{5}-\mathrm{e}\right)$, each $\mathrm{Fe}$ atom is in coordination with many $\mathrm{Fe}$ atoms (six and nine for $\mathrm{Ce}_{1} \mathrm{Fe}_{2}$-e and $\mathrm{Ce}_{1} \mathrm{Fe}_{5}-\mathrm{e}$, respectively). The strong exchange interaction renders the moments on the $\mathrm{Fe}$ atoms aligned in the same direction. Therefore, $\mathrm{Ce}_{1} \mathrm{Fe}_{2}$-e and $\mathrm{Ce}_{1} \mathrm{Fe}_{5}$-e exhibit ferromagnetic properties in the ground state. In the phases of $\mathrm{Ce}_{2} \mathrm{Fe}_{1}$-p and $\mathrm{Ce}_{1} \mathrm{Fe}_{1}$ $\mathrm{p}$, each Fe atom is only in coordination with two Fe atoms. The exchange interaction between $\mathrm{Fe}$ atoms is much weaker compared to those in the Fe-rich phases of Ce-Fe compounds. Such a weak exchange interaction between Fe atoms cannot force the electron spins of all the Fe atoms aligned in the same direction. As a result, there is no spin splitting of $3 \mathrm{~d}$ states of $\mathrm{Fe}$ for $\mathrm{Ce}_{2} \mathrm{Fe}_{1}$-p and $\mathrm{Ce}_{1} \mathrm{Fe}_{1}$-p phases. As seen in Fig. $\mathrm{S} 2, \dagger$ although no splitting between the spin-up and the spin-down states, the hybridization between the Fe $3 \mathrm{~d}$ states and the Ce $4 \mathrm{f}$ and $5 \mathrm{~d}$ states is also obvious. The Ce atoms in the $\mathrm{Ce}_{2} \mathrm{Fe}_{1}$-p and $\mathrm{Ce}_{1} \mathrm{Fe}_{1}$ $\mathrm{p}$ also adopt intermediate valence states, i.e. some $4 \mathrm{f}$ electrons of Ce are itinerant.

3.3.2 Ce-Co. For the Ce-Co compounds, only $\mathrm{Ce}_{1} \mathrm{Co}_{5}-\mathrm{e}$ exhibits ordered magnetic properties as shown in Table 1 and Fig. S3. $\dagger$ The arrangement of the magnetic moments of the ground magnetic state of $\mathrm{Ce}_{1} \mathrm{Co}_{5}$-e is the same as that of $\mathrm{Ce}_{1} \mathrm{Fe}_{5}-$ e, but with less negative relative energy ( $-69 \mathrm{meV}$ per atom) with respect to the nonmagnetic state. This result is easy understood because the structures of $\mathrm{Ce}_{1} \mathrm{Co}_{5}$-e and $\mathrm{Ce}_{1} \mathrm{Fe}_{5}$-e are the same and the magnetic properties of Co are similar to those of Fe but with weaker exchange interaction for Co than Fe. Besides the ground ferromagnetic state, there is also a metastable ordered magnetic state for $\mathrm{Ce}_{1} \mathrm{Co}_{5}$-e which is $\mathrm{O} \cdot \uparrow \uparrow \downarrow$ OOO (ferrimagnetic). Its relative energy with respect to the nonmagnetic state is $-1 \mathrm{meV}$ per atom, and much smaller (in absolute value) than that of the ferromagnetic state. Because the relative energy of the ferrimagnetic state with respect to the spindegenerate nonmagnetic state is very small, it should be not stable even at very low temperature.

The ground states of $\mathrm{Ce}_{2} \mathrm{Co}_{1}-\mathrm{p}, \mathrm{Ce}_{1} \mathrm{Co}_{1}-\mathrm{p}$ and $\mathrm{Ce}_{1} \mathrm{Co}_{2}-\mathrm{e}$ are all nonmagnetic (same for spin-polarized calculation and nonspin-polarized calculation). Note that the structure of $\mathrm{Ce}_{1} \mathrm{Co}_{2}$ e is the same as that of $\mathrm{Ce}_{1} \mathrm{Fe}_{2}$-e. The nonmagnetic ground state of $\mathrm{Ce}_{1} \mathrm{Co}_{2}$-e is surely due to the weak exchange interaction of Co. From Fig. S3 $\uparrow$ we can see that the PDOS of $\mathrm{Ce}_{2} \mathrm{Co}_{1}-\mathrm{p}, \mathrm{Ce}_{1} \mathrm{Co}_{1}-\mathrm{p}$ and $\mathrm{Ce}_{1} \mathrm{Co}_{2}$-e are similar to that of the corresponding $\mathrm{Ce}-\mathrm{Fe}$ phases except the non-spin-splitting. The distance between the main distribution of the $3 \mathrm{~d}$ states of the TM and that of the $4 \mathrm{f}$ states of $\mathrm{Ce}$ is a little larger for $\mathrm{Ce}_{2} \mathrm{Co}_{1}-\mathrm{p}$ and $\mathrm{Ce}_{1} \mathrm{Co}_{1}-\mathrm{p}$ phases than the corresponding $\mathrm{Ce}-\mathrm{Fe}$ phases. Thus, the hybridization between the Co $3 \mathrm{~d}$ states and the Ce $4 \mathrm{f}$ states is weaker in both Ce-Co phases than the Ce-Fe phases. For the Ce-Co phases, the hybridization between the Co $3 \mathrm{~d}$ states and the Ce $4 \mathrm{f}$ states is still strong although there is no spin-splitting in the $3 \mathrm{~d}$ states. So in the Ce-Co phases, the Ce $4 \mathrm{f}$ electrons are also partial itinerant.

3.3.3 Ce-Ni. For the Ce-Ni compounds, the electronic structures are similar to those of Ce-Co systems. Only $\mathrm{Ce}_{1} \mathrm{Ni}_{5}-\mathrm{e}$ exhibits ordered magnetic patterns, and it is also ferromagnetic. This is discrepancy with experiment, which is also encountered in the theoretical study. ${ }^{34}$ However, this must be regard as a minor one since the energy difference between the ferromagnetic state and the nonmagnetic state is only $-3 \mathrm{meV}$ per atom. The $\mathrm{Ce}_{1} \mathrm{Ni}_{1}$-p, $\mathrm{Ce}_{1} \mathrm{Ni}_{2}$-e and $\mathrm{Ce}_{1} \mathrm{Ni}_{3}$-e adopt nonmagnetic ground state based on our calculations. The Ce atoms in the phases of $\mathrm{Ce}_{1} \mathrm{Ni}_{2}$-e, $\mathrm{Ce}_{1} \mathrm{Ni}_{3}$-e and $\mathrm{Ce}_{1} \mathrm{Ni}_{5}$-e also adopt intermediate valence states due to the hybridization between the Ce4f states and Ni-3d states as shown in Fig. S4. $\dagger$

Very interestingly, as shown in Fig. S4, $\uparrow$ there is an energy gap in which the Fermi level is located for the phase of $\mathrm{Ce}_{1} \mathrm{Ni}_{1}-\mathrm{p}$, meaning that it is a semiconductor rather than a conductor. Its band structure is shown in Fig. 7. The computed band gap is $0.15 \mathrm{eV}$ at PBE level. To verify the existence of the band gap, we also used the Heyd-Scuseria-Ernzerhof (HSE06) exchangecorrelation functional. ${ }^{51}$ The computed HSE06 band gap is very close to the PBE value. From the PDOS, we see that the top of the valence band and the bottom of the conduction band are both mainly contributed by Ce-4f states. The appearance of the band gap at $E_{\mathrm{F}}$ suggests that all the Ce- $4 \mathrm{f}$ electrons become conducting electrons, i.e. they are delocalized. Thus, in the phase $\mathrm{Ce}_{1} \mathrm{Ni}_{1}-\mathrm{p}$, the Ce atoms are in tetravalent state which is different from all the other phases of Ce-TM compounds.

3.3.4 $\mathrm{Ce}-\mathrm{Cu}$ and $\mathrm{Ce}-\mathrm{Zn}$. For the $\mathrm{Ce}-\mathrm{Cu}$ compounds, $\mathrm{Ce}_{1} \mathrm{Cu}_{2}-\mathrm{e}, \mathrm{Ce}_{1} \mathrm{Cu}_{3}-\mathrm{p}, \mathrm{Ce}_{1} \mathrm{Cu}_{5}-\mathrm{p}, \mathrm{Ce}_{1} \mathrm{Cu}_{6}-\mathrm{e}$ possess magnetic properties in their ground states. As listed in Table 2 and shown in Fig. $\mathrm{S} 5, \uparrow$ the magnetic moments are only originated from $\mathrm{Ce}$ atoms in these $\mathrm{Ce}-\mathrm{Cu}$ phases. $\mathrm{Ce}_{1} \mathrm{Cu}_{2}$-e is in antimagnetic state, consistent with the experiment, ${ }^{32}$ while $\mathrm{Ce}_{1} \mathrm{Cu}_{3}-\mathrm{p}, \mathrm{Ce}_{1} \mathrm{Cu}_{5}-\mathrm{p}$ and $\mathrm{Ce}_{1} \mathrm{Cu}_{6}$-e are both in ferromagnetic states. Note that the energy difference between the ordered magnetic state and the nonmagnetic state for each phase is negligibly small. Thus, the magnetic properties can only be kept stable at extremely low temperature. Kondo effect may be responsible for the magnetic moments on $\mathrm{Ce}$ atoms since they are all $\mathrm{Cu}$-rich phases. For $\mathrm{Ce}_{1} \mathrm{Cu}_{1}-\mathrm{p}$, it's in a nonmagnetic ground state.

The magnetic properties of $\mathrm{Ce}-\mathrm{Zn}$ compounds are similar to those of $\mathrm{Ce}-\mathrm{Cu}$ compounds. $\mathrm{Ce}_{1} \mathrm{Zn}_{2}-\mathrm{e}, \mathrm{Ce}_{1} \mathrm{Zn}_{3}-\mathrm{e}, \mathrm{Ce}_{1} \mathrm{Zn}_{4}-\mathrm{p}$, $\mathrm{Ce}_{1} \mathrm{Zn}_{5}$-e and $\mathrm{Ce}_{1} \mathrm{Zn}_{7}-\mathrm{p}$ possess magnetic properties in their ground states. $\mathrm{Ce}_{1} \mathrm{Zn}_{3}$-e is in the antiferromagnetic state while $\mathrm{Ce}_{1} \mathrm{Zn}_{2}-\mathrm{e}, \mathrm{Ce}_{1} \mathrm{Zn}_{4}-\mathrm{p}, \mathrm{Ce}_{1} \mathrm{Zn}_{5}-\mathrm{e}$ and $\mathrm{Ce}_{1} \mathrm{Zn}_{7}-\mathrm{p}$ are all in ferromagnetic states. As in $\mathrm{Ce}-\mathrm{Cu}$ system, the energy differences between ground magnetic state and nonmagnetic state for $\mathrm{Ce}_{1} \mathrm{Zn}_{2}-\mathrm{e}, \mathrm{Ce}_{1} \mathrm{Zn}_{3}-\mathrm{e}, \mathrm{Ce}_{1} \mathrm{Zn}_{4}-\mathrm{p}, \mathrm{Ce}_{1} \mathrm{Zn}_{5}-\mathrm{e}$ and $\mathrm{Ce}_{1} \mathrm{Zn}_{7}-\mathrm{p}$ are also small. The reason for the magnetic properties of the $\mathrm{Zn}$-rich 

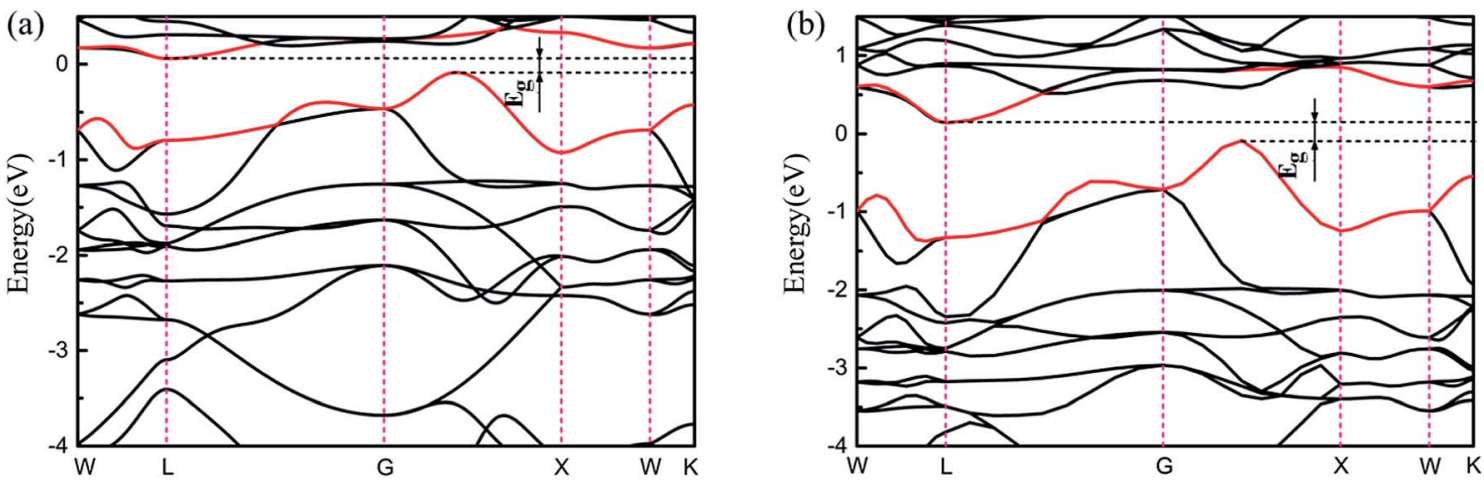

Fig. 7 (a) and (b) are the band structure of the $\mathrm{Ce}_{1} \mathrm{Ni}_{1}-\mathrm{p}$ phase using PBE and HSEO6 functional, respectively.

phases is also the Kondo effect. For $\mathrm{Ce}_{1} \mathrm{Zn}_{1}-\mathrm{p}$, its ground magnetic state is nonmagnetic state.

\subsection{Mechanical properties}

Considering the potential application of the Ce-TM compounds, we also computed their mechanical properties. The computed bulk modulus $B$ and shear modulus $G$ are listed in Table 1. Detailed elastic constants are listed in Table S1 (see the ESI $\dagger$ ). Based on the bulk modulus and shear modulus, Pugh $^{52}$ introduced a parameter $B / G$ to distinguish whether the material is ductile or brittle. When the value of $B / G$ is greater than 1.75 , this material is ductile, otherwise it is brittle. The values of $B / G$ for each phase are also listed in Table 1.

As listed in Tables 1 and $\mathrm{S} 1, \uparrow$ the calculated elastic constants and moduli of some experimental phases are in excellent agreement with the measured values..$^{53-56}$ Because Ce is a much softer material compared to the $3 \mathrm{~d}$ transition metals, the bulk moduli of Ce-TM compounds will increase as the concentration of the TM elements increases, as listed in Table 1. Among these different $\mathrm{Ce}-\mathrm{TM}$ compounds, $\mathrm{Ce}-\mathrm{Co}$ and $\mathrm{Ce}-\mathrm{Ni}$ compounds usually possess larger bulk moduli than the same composition $\mathrm{Ce}-\mathrm{Fe}, \mathrm{Ce}-\mathrm{Cu}$ and $\mathrm{Ce}-\mathrm{Zn}$ compounds. The bulk modulus reflects the ability of a substance resisting the compression, and it is in relation with the bond strength in this material. Because the metallic bonding arises from the electrostatic attractive force between the conduction electrons and the positively charged metal ions, the strength of the metallic bond in a metallic substance is dependent on the valence electrons of the metal elements. For the $\mathrm{Ce}-\mathrm{Fe}, \mathrm{Ce}-\mathrm{Co}$, and $\mathrm{Ce}-\mathrm{Ni}$ compounds, the $3 \mathrm{~d}$ electrons of the TM elements and some of the $4 \mathrm{f}$ and $5 \mathrm{~d}$ electrons of the Ce elements are conduction electrons. At the same composition, $\mathrm{Ce}-\mathrm{Fe}$ compound contains relatively less amount of conduction electrons than that of $\mathrm{Ce}-$ $\mathrm{Co}$ and $\mathrm{Ce}-\mathrm{Ni}$. The metallic bonds in $\mathrm{Ce}-\mathrm{Fe}$ compounds are relatively weaker than those in $\mathrm{Ce}-\mathrm{Co}$ and $\mathrm{Ce}-\mathrm{Ni}$ compounds. Hence, the bulk moduli of Ce-Fe compounds are smaller than those of the Ce-Co and Ce-Ni compounds. For $\mathrm{Ce}-\mathrm{Cu}$ and $\mathrm{Ce}-$ $\mathrm{Zn}$ compounds, because the valence electrons of $\mathrm{Cu}$ and $\mathrm{Zn}$ are $4 \mathrm{~s}$ electrons, the $4 \mathrm{f}$ electrons of Ce are localized, the conduction electrons in the $\mathrm{Ce}-\mathrm{Cu}$ and $\mathrm{Ce}-\mathrm{Zn}$ compounds are much less than those in the $\mathrm{Ce}-\mathrm{Fe}, \mathrm{Ce}-\mathrm{Co}$ and $\mathrm{Ce}-\mathrm{Ni}$ compounds. As such, the bond strength in the $\mathrm{Ce}-\mathrm{Cu}$ and $\mathrm{Ce}-\mathrm{Zn}$ compounds is weaker than that in $\mathrm{Ce}-\mathrm{Fe}, \mathrm{Ce}-\mathrm{Co}$ and $\mathrm{Ce}-\mathrm{Ni}$ compounds, which can result in relatively smaller bulk moduli.

The shear modulus reflects ability of the material resisting the shear stress, which is correlated with not only the bond strength but also the crystalline structure. For the same crystalline structure, as shown in Table 1, the Ce-Co and Ce-Ni compounds also possess the larger shear moduli. The values of the parameter $B / G$ for $\mathrm{Ce}-\mathrm{Fe}$, Ce-Co and $\mathrm{Ce}-\mathrm{Ni}$ are relatively larger than the critical value of 1.75 , which means they are more ductile, while for most phases of $\mathrm{Ce}-\mathrm{Cu}$ and $\mathrm{Ce}-\mathrm{Zn}$ compounds the values are smaller than 1.75 so that they are more brittle. The different ductility of some phases of the $\mathrm{Ce}-\mathrm{Cu}$ and $\mathrm{Ce}-\mathrm{Zn}$ compounds with those of the $\mathrm{Ce}-\mathrm{Fe}, \mathrm{Ce}-\mathrm{Co}$ and $\mathrm{Ce}-\mathrm{Ni}$ compounds may be due to the different states of the $4 \mathrm{f}$ electrons of Ce.

\section{Conclusion}

We have systematically studied phase stabilities, structures and the electronic properties, as well as mechanical properties of the binary compounds of cerium and 3d-transitional metal systems at ambient pressure and $0 \mathrm{~K}$, using the USPEX code coupled with first-principles calculations. For Ce-Sc, $\mathrm{Ce}-\mathrm{Ti}, \mathrm{Ce}-\mathrm{V}, \mathrm{Ce}-\mathrm{Cr}$ and Ce-Mn systems, no stable crystalline phases are found. For $\mathrm{Ce}-\mathrm{Fe}, \mathrm{Ce}-\mathrm{Co}, \mathrm{Ce}-\mathrm{Ni}, \mathrm{Ce}-\mathrm{Cu}$ and $\mathrm{Ce}-\mathrm{Zn}$ binary compounds, besides the experimentally observed phases, a number of new low-energy phases are predicted. The calculated phonon spectrum and elastic constants indicate that all the newly predicted phases are dynamically and mechanically stable. The detailed structures, electronic structures, magnetic properties, and mechanic properties of these structures are computed. The computed electronic structures indicate that there is obvious hybridization between the Ce-4f and Ce-5d states and the TM-3d states in the phases of $\mathrm{Ce}-\mathrm{Fe}, \mathrm{Ce}-\mathrm{Co}$ and $\mathrm{Ce}-\mathrm{Ni}$ compounds. So the $\mathrm{Ce}$ atoms in these phases are usually in intermediate valence states between $\mathrm{Ce}^{+3}$ and $\mathrm{Ce}^{+4}$. The Ce-4f states in the phases of $\mathrm{Ce}-\mathrm{Cu}$ and $\mathrm{Ce}-\mathrm{Zn}$ compounds are much more localized, indicating that the Ce atoms in these phases are in trivalent states. The TM-rich phases of $\mathrm{Ce}-\mathrm{Fe}, \mathrm{Ce}-\mathrm{Co}, \mathrm{Ce}-\mathrm{Ni}$ are usually in ferromagnetic ordering in their ground states, due to the strong exchange interaction between the TM elements. The 
$\mathrm{Cu}$-rich and Zn-rich phases of $\mathrm{Ce}-\mathrm{Cu}$ and $\mathrm{Ce}-\mathrm{Zn}$ compounds also exhibit magnetic properties where magnetic moments are only located on Ce atoms, due to the Kondo effects. The relative larger bulk moduli indicate that $\mathrm{Ce}-\mathrm{Co}$ and $\mathrm{Ce}-\mathrm{Ni}$ compounds have relatively higher ability to resist compression. The computed Pugh parameter $B / G$ suggests that most of $\mathrm{Ce}-\mathrm{Cu}$ and $\mathrm{Ce}-\mathrm{Zn}$ compounds may be more brittle because of the more localized states of Ce-4f electrons in the $\mathrm{Ce}-\mathrm{Cu}$ and $\mathrm{Ce}-\mathrm{Zn}$ compounds while those of $\mathrm{Ce}-\mathrm{Fe}, \mathrm{Ce}-\mathrm{Co}$ and $\mathrm{Ce}-\mathrm{Ni}$ may be more ductile. Our results offer important new data which will be useful for better understanding of intriguing behavior of $\mathrm{Ce} 4 \mathrm{f}$ electrons in Ce-TM compounds. The predicted new phases of the Ce-TM binary compounds will also motivate future experimental confirmation.

\section{Conflicts of interest}

There are no conflicts to declare.

\section{Acknowledgements}

This work is supported by the National Natural Science Foundation of China (Grant No. 51322103, 5160010435, 11404085, 11104056), NSAF (Grant No. U1630118), MOST 973 Program (Grant No. 2015CB856800) and the Fundamental Research Funds for the Central Universities in China. The numerical calculations in this paper are supported by the supercomputing system in the Supercomputing Center of University of Science and Technology of China. XCZ is supported by a Qianren-B fund (1000 Talents Plan B for summer research) from USTC and a State Key R\&D Fund of China (2016YFA0200604) to USTC.

\section{References}

1 B. Johansson, Philos. Mag., 1973, 30, 469-482.

2 E. King, J. A. Lee, I. R. Harris and T. F. Smith, Phys. Rev. B: Condens. Matter Mater. Phys., 1970, 1, 1380.

3 J. W. Allen and R. M. Martin, Phys. Rev. Lett., 1982, 49, 1106. 4 E. G. Ponyatovskii, Dokl. Akad. Nauk SSSR, 1958, 120, 1021.

5 A. Cadien, Q. Y. Hu, Y. Meng, Y. Q. Cheng, M. W. Chen, J. F. Shu, H. K. Mao and H. W. Sheng, Phys. Rev. Lett., 2013, 110, 125503.

6 J. M. Léger, Phys. B, 1993, 190, 84-91.

7 H. W. Sheng, H. Z. Liu, Y. Q. Cheng, J. Wen, P. L. Lee, W. K. Luo, S. D. Shastri and E. Ma, Nat. Mater., 2007, 6, 192-197.

8 Q. S. Zeng, Y. Ding, W. L. Mao, W. Yang, S. V. Sinogeikin, J. Shu, H. K. Mao and J. Z. Jiang, Phys. Rev. Lett., 2010, 104, 105702.

9 G. Seyfarth, A. S. Rüetschi, K. Sengupta, A. Georges, D. Jaccard, S. Watanabe and K. Miyake, Phys. Rev. B: Condens. Matter Mater. Phys., 2012, 85, 205105.

10 H. L. Luo, M. B. Maple, I. R. Harris and T. F. Smith, Phys. Lett. A, 1968, 27, 519-520.

11 Y. Ōnuki and T. Komatsubara, J. Magn. Magn. Mater., 1987, 63, 281-288.
12 M. B. Tang, H. Y. Bai, W. H. Wang, D. Bogdanov, K. Winzer, K. Samwer and T. Egami, Phys. Rev. B: Condens. Matter Mater. Phys., 2007, 75, 172201.

13 S. V. Streltsov, E. Gull, A. O. Shorikov, M. Troyer, V. I. Anisimov and P. Werner, Phys. Rev. B: Condens. Matter Mater. Phys., 2012, 85, 195109.

14 F. M. G. N. D. Mathur, S. R. Julian, I. R. Walker, D. M. Freye, R. K. W. Haselwimmer and G. G. Lonzarich, Nature, 1998, 394, 39-43.

15 A. P. Murani, S. J. Levett and J. W. Taylor, Phys. Rev. Lett., 2005, 95.

16 T. Yamaguchi, N. Ikeda, H. Hattori and K. Tanabe, J. Catal., 1981, 67, 324-330.

17 M. Ozawa, J. Alloys Compd., 1998, 275, 886-890.

18 C. A. Luengo, A. L. Cabrera, H. B. MacKay and M. B. Maple, J. Catal., 1977, 47, 1-10.

19 B. Zhang, D. Q. Zhao, M. X. Pan, R. J. Wang and W. H. Wang, Acta Mater., 2006, 54, 3025-3032.

20 B. Zhang, D. Q. Zhao, M. X. Pan, W. H. Wang and A. L. Greer, Phys. Rev. Lett., 2005, 94, 205502.

21 S. F. Matar, Prog. Solid State Chem., 2013, 41, 55-85.

22 C. Becle and R. Lemaire, Acta Crystallogr., 1967, 23, 840-845.

23 J. G. Park, Philos. Mag. B, 1993, 68, 653-662.

24 P. Krypyakevich and I. I. Zalutskii, Dopov. Akad. Nauk Ukr. $R S R, 1965,31,54-56$.

25 L. Colombo, G. L. Olcese and G. B. Bonino, Atti Accad. Naz. Lincei, Cl. Sci. Fis., Mat. Nat., Rend., 1963, 35, 53-57.

26 A. C. Lawson, J. M. Lawrence, J. D. Thompson and A. Williams, Phys. B, 1990, 163, 587-590.

27 H. Asmat, B. Barbara and D. Gignoux, J. Solid State Chem., 1977, 22, 179-184.

28 I. Vedel, A. M. Redon, J. M. Mignot and J. M. Leger, J. Phys. F: Met. Phys., 1987, 17, 849-856.

29 R. A. F. G. E. Brodale, E. P. Norman and J. Floquet, Phys. Rev. Lett., 1986, 56, 390.

30 B. D. R. M. Loewenhaupt and F. Steglich, Phys. Rev. Lett., 1979, 42, 1709.

31 K. H. J. Buschow and H. V. Daal, AIP Conf. Proc., 1972, 5, 1464-1477.

32 E. Gratz, E. Bauer, B. Barbara, S. Zemirli, F. Steglich, C. D. Bredl and W. Lieke, J. Phys. F: Met. Phys., 1985, 15, 1975-1986.

33 T. M. Seixas and J. M. da Silva, Phys. B, 1999, 269, 362-367. 34 L. Nordström, M. S. S. Brooks and B. Johansson, Phys. Rev. B: Condens. Matter Mater. Phys., 1992, 46, 3458-3464.

35 C. W. Glass, A. R. Oganov and N. Hansen, Comput. Phys. Commun., 2006, 175, 713-720.

36 A. R. Oganov and C. W. Glass, J. Chem. Phys., 2006, 124, 244704.

37 A. R. Oganov, Y. Ma, Y. Xu, I. Errea, A. Bergara and A. O. Lyakhov, Proc. Natl. Acad. Sci. U. S. A., 2010, 107, 7646-7651.

38 C. H. Hu, A. R. Oganov, Q. Zhu, G. R. Qian, G. Frapper, A. O. Lyakhov and H. Y. Zhou, Phys. Rev. Lett., 2013, 110, 165504.

39 Q. Li, Y. Ma, A. R. Oganov, H. Wang, H. Wang, Y. Xu, H. K. Mao and G. Zou, Phys. Rev. Lett., 2009, 102, 175506. 
40 Y. L. Li, S. N. Wang, A. R. Oganov, H. Gou, J. S. Smith and T. A. Strobel, Nat. Commun., 2015, 6, 6974.

41 J. F. l. G. Kresse, Phys. Rev. B: Condens. Matter Mater. Phys., 1996, 54, 11169.

42 J. P. Perdew, K. Burke and M. Ernzerhof, Phys. Rev. Lett., 1996, 77, 3865-3868.

43 O. Eriksson, L. Nordström, M. S. S. Brooks and B. Johansson, Phys. Rev. Lett., 1988, 60, 2523.

44 L. Nordström, O. Eriksson, M. S. S. Brooks and B. Johansson, Phys. Rev. B: Condens. Matter Mater. Phys., 1990, 41, 9111.

45 A. Togo and I. Tanaka, Scr. Mater., 2015, 108, 1-5.

46 M. Born and K. Huang, Dynamical Theory of Crystal Lattices, Clarendon press, 1954.

47 D. Liu, X. Dai, X. Wen, G. Qin and X. Meng, Comput. Mater. Sci., 2015, 106, 180-187.

48 Z. J. Wu, E. J. Zhao, H. P. Xiang, X. F. Hao, X. J. Liu and J. Meng, Phys. Rev. B: Condens. Matter Mater. Phys., 2007, 76, 054115.
49 R. Golesorkhtabar, P. Pavone, J. Spitaler, P. Puschnig and C. Draxl, Comput. Phys. Commun., 2013, 184, 1861-1873.

50 S. J. Kennedy, P. J. Brown and B. R. Coles, J. Phys.: Condens. Matter, 1993, 5, 5169-5178.

51 J. Heyd, G. E. Scuseria and M. Ernzerhof, J. Chem. Phys., 2003, 118, 8207-8215.

52 S. F. Pugh, London, Edinburgh Dublin Philos. Mag. J. Sci., 1954, 45, 823-843.

53 K. Nassau, L. V. Cherry and W. E. Wallace, J. Phys. Chem. Solids, 1960, 16, 123-130.

54 Y. Khan, J. Less-Common Met., 1974, 34, 191-200.

55 B. Butler, D. Givord, F. Givord and S. B. Palmer, J. Phys. C: Solid State Phys., 1980, 13, L743-L746.

56 L. G. Hector and J. F. Herbst, J. Alloys Compd., 2004, 379, 4153. 